\title{
Diversity of coronavirus receptors
}

Pritha Ghosh ${ }^{1}$, Savita Jayaram ${ }^{1}$, Dhruti Patwardhan ${ }^{1}$, Saranya Marimuthuㄹ, Patrick Lenehan², AJ Venkatakrishnan ${ }^{2}$, Travis Hughes ${ }^{2}$, David Zemmour ${ }^{2}$, Praveen Anand ${ }^{1 *}$, Venky Soundararajan ${ }^{1,2^{*}}$.

\author{
${ }^{1}$ nference Labs, 2nd Floor, 22 3rd Cross Rd, Murgesh Pallya, Bengaluru, Karnataka 560017, India \\ ${ }^{2}$ nference, One Main Street, East Arcade, Cambridge, MA 02142, USA \\ *Address correspondence to Praveen Anand (praveen@nference.net), Venky Soundararajan \\ (venky@nference.net)
}

\section{Abstract}

Several recent surges in COVID-19 cases due to newly emerging variant strains of SARSCoV-2 with greater transmissibility have highlighted the virus's capability to directly modulate spike-ACE2 interactions and promote immune evasion by sterically masking the immunogenic epitopes. Recently, there have also been reports of the bidirectional transfer of coronavirus between different animal species and humans. The ability of coronavirus to infect and adapt to a wide range of hosts can be attributed to new variants that modify the molecular recognition profile of the spike protein (S protein). The receptorbinding domain of the spike protein specifically interacts with key host receptor molecules present on the host cell membranes to gain entry into the host and begin the infection cycle. In this review, we discuss the molecular, structural, and functional diversity associated with the coronavirus receptors across their different phylogenetic lineages and its relevance to various symptomatology in the rapid human-to-human infection in COVID19 patients, tropism, and zoonosis. Despite this seeming diversity of host receptors, there may be some common underlying mechanisms that influence the host range, virus transmissibility, and pathogenicity. Understanding these mechanisms may be crucial in not only controlling the ongoing pandemic but also help in stopping the resurgence of such virus threats in the future.

Keywords: coronavirus, SARS-CoV-2, receptors, COVID-19, pandemic

\section{Introduction}

The Coronavirus (CoV) genus belongs to the family Coronaviridae and order Nidovirales [1-5]. It is mainly responsible for causing infections of the respiratory and gastrointestinal tracts and the central nervous system of mammals (including humans) and birds $[4,5]$. Coronaviruses are enveloped, non-segmented, positive-stranded RNA viruses, with a typical genome size of 27 - $32 \mathrm{~kb}$ (largest among all RNA viruses), a 5'-capped structure, and a $3^{\prime}$ poly-A tail [3, 6-8]. 
The relatively large and diverse Coronaviridae family is divided into two subfamilies: Letovirinae and Orthocoronavirinae $[6,9]$. The Orthocoronavirinae subfamily is classified into four major genera: Alphacoronavirus (including the human coronaviruses HCoV-NL63 and HCoV-229E), Betacoronavirus (including the human coronaviruses HCoV-OC43, HCoV-HKU1, severe acute respiratory syndrome coronavirus (SARS-CoV), and Middle East respiratory syndrome coronavirus (MERS-CoV), Gammacoronavirus and Deltacoronavirus. Of these, the alpha and the beta genera infect mammals (mainly bat and rodent reservoirs), whereas the gamma and the delta predominantly infect birds $[3-5,10,11]$. In terms of pathogenicity, SARS-CoV and MERS are highly infectious zoonotic pathogens responsible for two significant epidemics in the recent past (Figure 1A). Compared to these, HCoV-OC43, HCoV-HKU1, HCoV-NL63, and HCoV-229E only cause mild illnesses with symptoms similar to the common cold in infected humans.

COVID-19 is the most recent pandemic caused by a novel coronavirus named SARS-CoV-2 [12], which started in early December 2019 in China's Wuhan City [13-15] and was declared to be a "pandemic" by WHO in March 2020. As of 15 January 2021, the COVID-19 pandemic is still progressing at an alarming rate, resulting in over 90 million infections and almost two million deaths worldwide (Coronavirus disease (COVID-19) Pandemic: WHO). The Severe Acute Respiratory Syndrome coronavirus (SARS-CoV), Middle East respiratory syndrome coronavirus (MERS-CoV), and SARS-CoV-2 outbreaks within a short span of two decades, and the ability of coronaviruses to transmit from animals-to-humans and humans-to-humans pose a great threat to human health. For example, SARS-CoV is known to be transmitted from rhinolophid bats to the carnivorous wild game (like civet cats) to humans [16-18]. Many SARS-related coronaviruses (SARSr-CoVs) in bats also can infect humans [18-21]. Three novel swine coronaviruses have also emerged in the 21st century. The novel swine acute diarrhea syndrome coronavirus (SADS-CoV), causing $90 \%$ mortality in pigs, was shown to replicate efficiently in primary human lung and intestinal cells, demonstrating very high-risk zoonotic transmissions [22]. Recent work has shown the phylogenetic relationship between members of the orthocoronavirus subfamily [6]. Specifically, a maximum likelihood (ML) phylogenetic tree based on amino acid sequences of open reading frame 1ab (ORF1ab) has highlighted the diversity of coronaviruses and shown that human coronaviruses have likely evolved from those of domesticated animals and rodents. Their study suggests that coronavirus transmissions have occurred multiple times in evolutionary history, from animals to humans.

The spike protein is a transmembrane homotrimeric protein that protrudes from the viral surface, giving coronaviruses the signature crown-like appearance (hence the name; corona meaning crown in Latin). Spike-receptor interaction is a crucial step in the viral infection cycle. Viral receptors on the surface of host cells will determine the host range of the virus and its ability to cross species barriers. Various biophysical studies have been performed to identify the potential receptors of coronaviruses since the 2003 epidemic that has helped us identify them in an unbiased way through literature signals (Figure 1B). In this review, we will discuss the diversity of these receptors across coronavirus host species and how the virus might have evolved mechanisms to gain entry into a broad range of hosts. We will explore the expression, localization, evolutionary conservation, and binding affinity of these receptors to understand a common theme adopted by the 
virus to identify cell surface molecules as their receptors. We will also delve into the known structures of the spike proteins in complex with its receptors to understand the spikereceptor interaction mode.

A

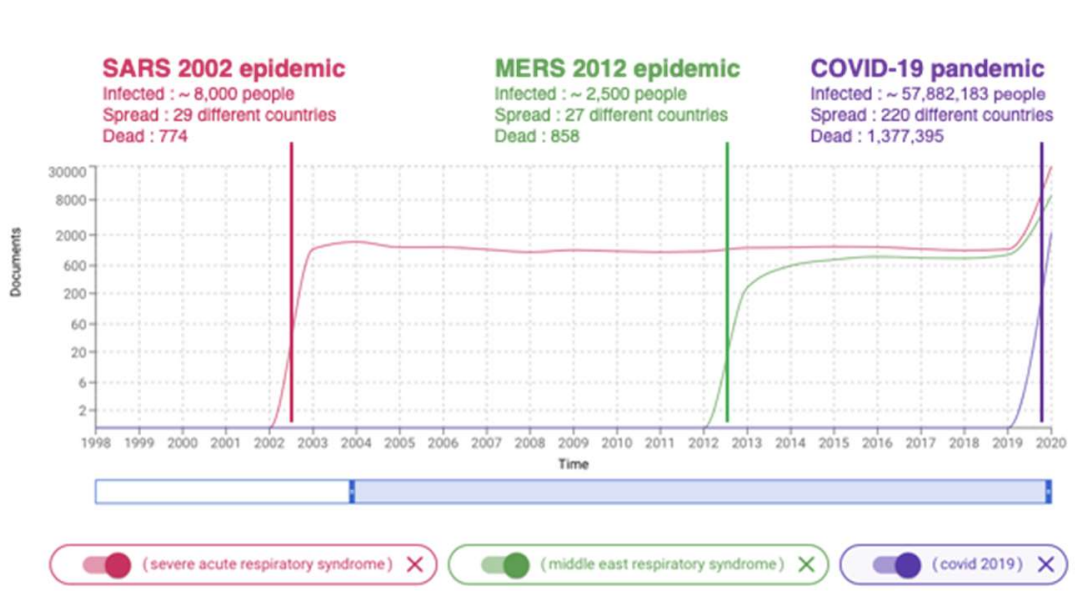

B

\begin{tabular}{|c|c|c|}
\hline Protein receptor molecule & $\begin{array}{l}\text { Local } \\
\text { score }\end{array}$ & $\begin{array}{l}\text { Global } \\
\text { score }\end{array}$ \\
\hline angiotensin converting enzyme 2 & 6.9 & 2.0 \\
\hline aminopeptidase $n$ & 5.0 & 1.7 \\
\hline बpp4 & 5.0 & 2.5 \\
\hline de sign & 3.1 & 2.3 \\
\hline ed2091 & 3.0 & 2.6 \\
\hline (1) ceacam1 & 3.1 & $<1.3$ \\
\hline
\end{tabular}

Figure 1: (A) Timelines depict the surge in PubMed records for coronaviruses that were responsible for three epidemics - SARS, MERS, and the most recent COVID-19. (B) Literature signals for various biomolecules identified as receptors using nferX signals [23].

\section{Coronavirus genome organization and infection cycle}

The coronavirus genome organization is similar to that of the other members of the Nidovirales order, with the non-structural proteins (involved in genome replication, proteolytic processing, and sub-genomic transcription) being encoded by the 5'-proximal end covering two-thirds of the genome, and the major structural proteins (in 5'-3' order: spike (S), envelope (E), membrane (M), and nucleocapsid $(N)$ ) being encoded by rest of the genome at the 3' proximal end $[6,24]$. The non-structural proteins nsp1 to nsp11 (11 proteins) and nsp12 to nsp16 (5 proteins) are encoded by ORF1a (translated directly from genomic RNA) and ORF1b (translated after a -1 ribosomal frameshift near the end of ORF1), respectively [6]. The structural proteins encoded downstream of the ORF1ab polypeptide are involved in receptor-binding and membrane fusion (S), viral assembly and budding ( $E$ and $M$ ), and nucleocapsid formation $(N)$. The coronavirus genomic RNA is packaged inside a helical capsid and further surrounded by an envelope. The structural proteins associated with the viral envelope aid in the virus assembly and the entry of the virus into the host cells [3]. In some cases, an envelope-associated hemagglutininesterase protein (HE) is present in some coronavirus species to aid in cellular entry [25].

The first step of the viral life-cycle is the binding of the viral spike protein to the host cell receptor [26-29]. This interaction triggers a conformational change in the spike protein that enables the fusion of the viral envelope and the host cell membrane for viral 
entry. Upon entry into the host cell, uncoating the virion releases its genomic RNA into the cytoplasm. This is immediately followed by the translation of two large open reading frames, ORF1a and ORF1b, to produce two large viral precursor polyproteins, pp1a and pp1ab, respectively. These polyproteins are then co-translationally and posttranslationally processed by viral proteinases to smaller non-structural proteins (nsps) involved in viral replication and transcription. Discontinuous transcription of the viral RNA leads to the production of both genomic and subgenomic mRNAs, which encode the structural proteins necessary for generating the virion. These newly translated structural proteins translocate through the endoplasmic reticulum (ER) and transit through the ERto-Golgi intermediate compartment (ERGIC), where they interact with the newly produced $\mathrm{N}$-encapsidated genomic RNA resulting in budding into the lumen of secretory vesicular compartments. The freshly synthesized virions are then exocytosed from the infected host cell and are ready to infect a fresh set of host cells.

\section{Cross-species transmission contributes to the emergence of novel coronavirus strains}

Cross-species transmission of coronavirus poses a significant challenge to the control of disease spread. The majority of the virus outbreaks are caused by microevolution of the virus in response to the wide range of physiological and immunological pressure posed by different host reservoirs [30,31]. In coronaviruses, this spillover mechanism is evidenced by the similarity observed in genomic sequences across either the coronaviruses or their corresponding host receptors $[32,33]$. The beta coronaviruses consist of four distinct lineages annotated as lineage $A, B, C$, and $D$ based on their phylogenetic similarity. Lineage A includes human coronaviruses HKU1 and OC43. The phylogenetic analysis of SARS-CoV-2 with other beta coronaviruses shows that it clusters closely with certain bat coronaviruses within lineage $B$, especially Bat-SARSr-CoV RaTG13. A phylogenetic tree based on nucleotide sequences of complete genomes of coronaviruses also revealed that SARS-CoV-2 is more similar to Bat-SARSr-CoV RaTG13, sharing 96\% sequence identity in comparison to SARS-CoV with just over $79 \%$ sequence identity, hinting at the possible bat origin of COVID-19 [34]. The highly pathogenic MERS coronaviruses fall within lineage $\mathrm{C}$ and coronaviruses infecting bats in lineage D. A multiple sequence alignment between all the SARS coronaviruses spike protein sequences was done to assess the degree of sequence identity between them (Figure 2A).

The lineage trend of SARS-CoV-2 traces its original emergence in bat species (Rhinolophus affinis) followed by transmission to humans through Malayan pangolins (Manis javanica) [35-37]. This deadly zoonotic virus is transmitted to other animal species in close contact with humans [38-41]. In April 2020, SARS-CoV-2 spillover in Denmark mink farms from humans was identified and found to have spread across multiple mink farms within a short period [39]. The most alarming fact of this incident is the concurrent bidirectional transmission that introduced mink-adapted SARS-CoV-2 genomes to the human population, potentially contributing to the emergence of more pathogenic SARS- 
CoV-2 strains. Even though such a large-scale outbreak is not reported in other animal species, researchers have evaluated the SARS-CoV-2 susceptibility in a few other animal species that are likely to be in contact with the human using animal models. These studies revealed that domestic animals such as dogs [42], cats [42], ferrets [42, 43], hamsters [44, 45], and rabbits [46] are also susceptible to SARS-CoV-2 infection.



Figure 2: Phylogenetic analyses of spike protein sequences. (A) The $S$ protein sequences of SARS-CoV-2, along with chosen representatives from all the four betacoronavirus lineages listed in the study by Jaimes et al. [34], were aligned using MAFFT [47]. A maximum-likelihood tree was generated based on the alignment, and the tree was rooted using the alphacoronavirus $S$ protein sequence HCoV-229E. The number at the nodes indicates the bootstrap support (100 replicates). (B) The protein domain 
architecture of SARS-CoV-2 S protein. The multiple sequence alignment snapshots corresponding to regions comprising receptor binding motif, S1/S2 cleavage site, and fusion peptide areis depicted.

The host-receptor recognition is one of the initial species barriers overcome by the virus during cross-species transmission $[48,49]$. The Pangolin-CoV identified as a distant relative to SARS-CoV-2 exhibits a high sequence similarity ( $97 \%)$ in the spike protein and similarly binds to human ACE2 $[37,50]$. Such observations support the fact that human coronaviruses emerge through a successive accumulation of mutations that alter host-specificity acquired through various events such as genetic recombination or low fidelity of RNA-dependent RNA polymerase (RdRp) or due to replication slippage. Moreover, scanning for similarity of cell-surface molecules across multiple known host species can reveal their susceptibility [49, 51]. Overall, comprehensive sequence surveillance of closely related viruses with different host species is recommended to predict outbreaks and implement appropriate public precautionary measures.

\section{Role of spike protein and glycosylation in coronavirus infection}

\section{Domain organization of spike protein}

TThe spike protein consists of two major subunits, S1 (receptor-binding subunit) and S2 (membrane-fusion subunit) followed by a transmembrane anchor region, and a short intracellular tail $[3,52,53]$ (Figure 3B). A novel feature that sets SARS-CoV-2 apart from SARS-CoV and SARSr-CoVs is the presence of a 'furin' cleavage site (FCS) at the S1/S2 boundary [54], a feature conserved among almost all the SARS-CoV-2 isolates sequenced to date (Table 1). However, this site is found to be ubiquitous in other members of coronavirus such as in gammacoronaviruses, Embecovirus and a few strains of betacoronaviruses (MERS-CoV, bat coronavirus HKU), feline coronavirus (UCD, UCD8), and canine coronavirus $[55,56]$. The presence of this additional cleavage site aids its pathogenicity leading to increased transmissibility [57-59]. Interestingly, this cleavage site (682-RRAR|SVAS-689) was observed to be identical to the furin cleavage site present in the alpha subunit of the human epithelial sodium ion channel (ENaC) protein [60]. Furin plays a vital role in the activation of $\mathrm{ENaC}$ alpha through proteolytic processing at this site. The severe respiratory symptoms observed in COVID-19 patients can be potentially due to the hijacking of this furin cleavage site, leading to inactivated $\mathrm{ENaC}$ and thus disrupt the homeostasis of airway surface liquid. This hijacking could also potentially explain the lower rate of SARS-CoV-2 infection in cystic fibrosis patients. They are observed to overexpress $\mathrm{ENaC}$ alpha that can sequester the furin protease and prevent the furin-mediated activation of the SARS-CoV-2 virus [61, 62]. Following the cleavage, in all coronaviruses, the $\mathrm{S} 1$ subunit remains covalently bound to $\mathrm{S2}$, contributing to the stability of the prefusion complex. In contrast, the membrane-anchored S2 subunit is further cleaved at the S2' site by host proteases triggering membrane fusion 
and viral entry mediated by extensive conformational changes [63-68]. Importantly, spike protein trimers in highly pathogenic coronaviruses appear to exist in partially open states or spontaneously alternate between closed and open conformations unlike the largely closed conformations seen in common cold-causing coronaviruses [54].

The fusion peptide region of spike-protein is highly conserved across all the coronaviruses. This implies that the mechanism driving the process of membrane fusion resulting in the release of the virus into the host cytoplasm is well conserved. In contrast, the receptor-binding motif region was observed to be highly variable due to various insertions and deletions (Figure 2B). A four amino acid insertion (681-PRRA-684) at the $\mathrm{S} 1 / \mathrm{S} 2$ boundary that is a unique feature among lineage $\mathrm{B}$ was found in SARS-CoV-2 but is not shared by either SARS-CoV or the Bat-SARSr-CoV RaTG13 (Figure 2B). This insertion is predicted to form a protruding loop structure that makes the SARS-CoV-2 $\mathrm{S} 1 / \mathrm{S} 2$ site more easily accessible to cleavage by host proteases, suggesting this region could be a key driver of viral evolution.

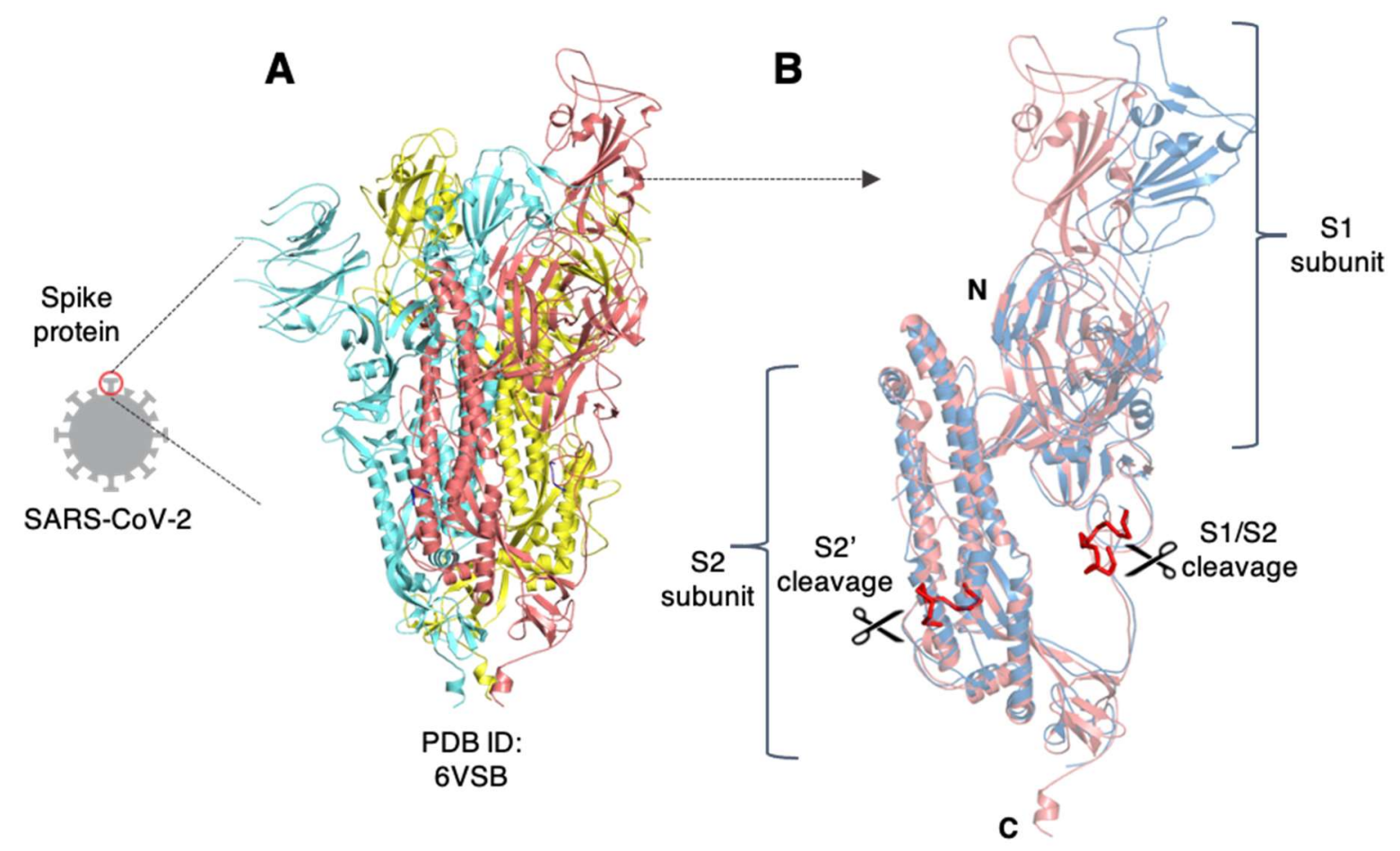

Figure 3: (A) The cartoon representation of homotrimeric spike protein from SARS-CoV2 (PDB ID: 6VSB). (B) Cartoon representation depicting the structural superposition of closed (red) and the open form of single spike protein subunit. The S1/S2 and the S2' cleavage sites are depicted in the red wireframe.

Depending on the viral species, different coronaviruses use distinct domains within the $\mathrm{S} 1$ subunit to recognize a variety of host receptors. The $\mathrm{S} 1$ subunit can be divided into two domains, the N-terminal domain (NTD or S1A) and the C-terminal domain (CTD or S1B), one or both of which can function as receptor-binding domains (RBDs), that dictate the range of hosts for these coronaviruses [69-71]. To date, the S1-NTD has been observed to recognize either protein or sugar receptors, whereas the S1-CTD recognizes 
only protein receptors [71]. It is interesting to note that S1-CTDs of coronaviruses from different genera can recognize the same protein receptor, but in contrast, those from the same genus can recognize different receptors. The $S$ gene encoding the spike protein in SARS-CoV-2 is divergent (less than $75 \%$ sequence identity) from those of SARS-CoV and other Bat-SARSr-CoVs (from the betacoronavirus genus), except for a high sequence identity (over 93\%) to that of the Bat-SARSr-CoV RaTG13 $[72,73]$. The S gene in SARSCoV-2 is longer than those in other SARSr-CoVs, with three short insertions in the region encoding the S1-NTD [72]. The spike proteins from SARS-CoV (isolated from human, civet, or bat) and SARS-CoV-2 share an overall global protein sequence similarity ranging from $76-78 \%$, with just $50-53 \%$ similarity observed within the receptor-binding motif (RBM) present within the receptor-binding domain [73]. It should be noted that four out of the five key residues that interact with the Angiotensin-converting enzyme 2 (ACE2) receptor (see also the Molecular Diversity of Coronavirus Receptors section) in the RBM of SARS-CoV-2 differ in SARS-CoV [72].

A
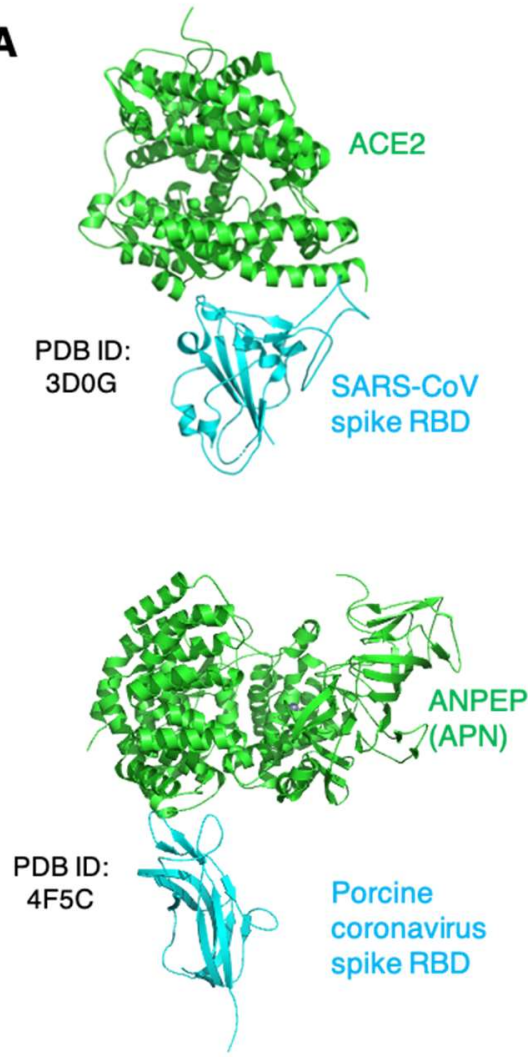

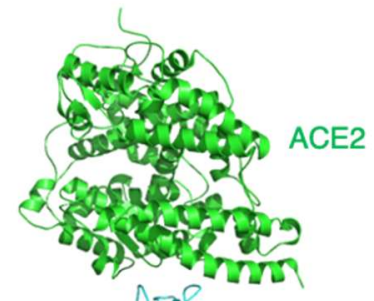

PDB ID: 3KBH

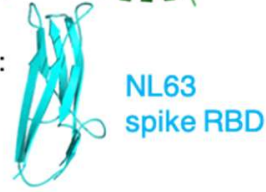

PDB ID
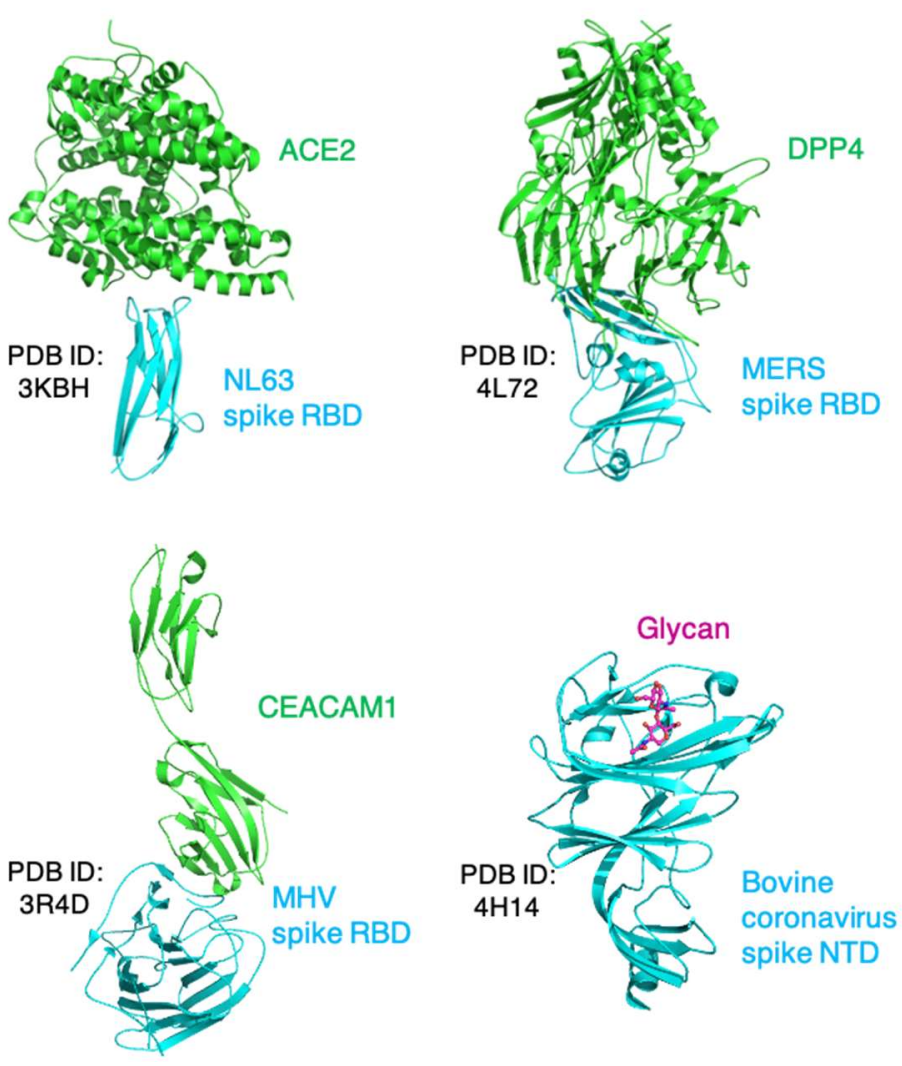


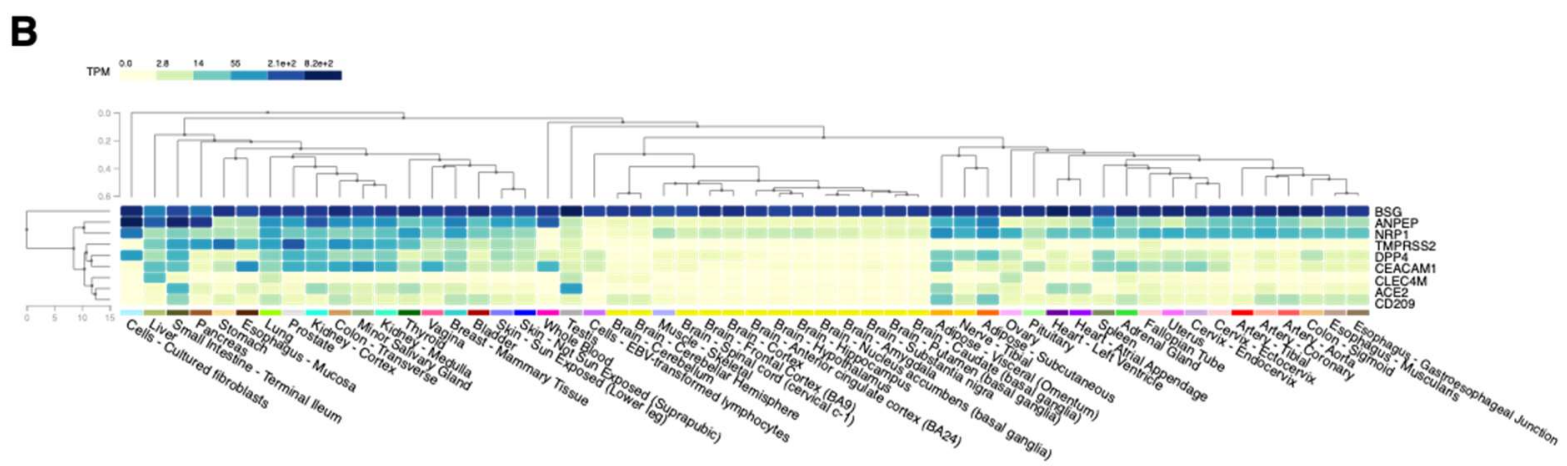

Figure 4: Diversity of coronavirus receptors. (A) Cartoon representation of experimentally determined crystal structures of receptor binding domains from various coronavirus spike proteins (cyan) with the corresponding protein (green) or glycan (magenta) host receptors. (B) Heatmap depicting the expression of various host-receptor molecules across normal tissues from the GTEx study.

\section{Molecular recognition of host receptors through coronavirus spike proteins}

The crystal structures of S1 domains of five coronaviruses complexed with their receptors have been deduced since the SARS pandemic. These include complexes of SARS-CoV S1-CTD [74] and HCoV-NL63 S1-CTD with human ACE2 [75], MERS-CoV S1-CTD with human DPP4 [76], porcine coronavirus PRCV S1-CTD with porcine APN [77], and mouse hepatitis coronavirus MHV S1-NTD with murine CEACAM1 [78]. Additionally, the crystal structure of bovine coronavirus, BCoV S1-NTD, that uses sialic acid as a receptor has been independently determined, along with its sugar-binding site that was identified through mutagenesis [79] (Figure 4A). These six structures have revealed the complex interplay between coronaviruses and their receptors and how they use complicated evolutionary strategies to recognize them (reviewed in [71]). Apart from this, more variant forms of these six representative structures have also been determined, including S1CTD of a MERS-CoV-related bat coronavirus HKU4 complexed with human DPP4 and S1-CTDs of other SARS-CoV strains complexed with ACE2 from animals [79, 81, 82]. The specific molecular interaction between ACE2 and the SARS-CoV-2 has also been characterized well through experimental crystallography and described in the latter part of the review. The S1-CTDs of MERS-CoV and HKU4 similarly recognize DPP4, indicating a close evolutionary relationship between the two viruses $[81,83]$. Although the core structures of SARS-CoV and MERS-CoV S1-CTDs are very similar, the RBMs are markedly different, suggesting different evolutionary pathways and recognizing different receptors. Alternately, alphacoronaviruses HCoV-NL63 S1-CTD and betacoronavirus SARS-CoV sport very different tertiary structures, but both recognize ACE2, hinting at divergent evolution [71]. A virus-binding hotspot Lys353 on ACE2 was identified to play a critical role in binding these two different coronaviruses [84]. 


\section{Glycosylation of spike protein}

Many cell-surface proteins and lipids are conjugated with sugar moieties. They play a significant role in cell-cell communication and immune processes [85-87]. Coronaviruses specifically utilize this glycan shielding to limit the immune system $[54,88,89]$. The spike trimers are highly covered with both $\mathrm{N}$-linked and O-linked glycans [88-90], which modulate surface accessibility to host proteases [90] and neutralizing antibodies [54, 89, 91] and are also crucial for proper folding [92]. Notably, except for the ACE2 binding domain, glycosylation shields approximately $40 \%$ of the surface of the spike protein trimers [93]. As per the cryo-EM map, 16 of the 22 predicted N-glycosylation sites (N-X$\mathrm{S} / \mathrm{T}$, where $\mathrm{X}$ is any amino acid except $\mathrm{P}$ ) were resolved in SARS-CoV-2 spike protein, of which 20 are conserved in SARS-CoV spike protein and at least 19 of them have been experimentally confirmed to be glycosylated in SARS-CoV spike protein [54] (Figure 5A, 5B). Although a low O-linked occupancy was observed in spike protein in its native state [94], 26 O-glycosylation sites and 33 O-linked glycans were unambiguously identified in SARS-CoV-2 spike protein using Signature lons-Triggered Electron-Transfer/HigherEnergy Collisional Dissociation (EThcD) Mass Spectrometry [95]. Interestingly, spike protein is O-glycosylated on a threonine (T678) present near the furin cleavage site (682685) [96]. This may be biologically important because the O-glycans present in the vicinity of the cleavage site of a protein may regulate the proteolytic cleavage of spike protein and even affect the activation of the virus. The difference in glycosylation patterns can also affect the conformation of spike protein, and it has been confirmed through biochemical experiments that deletion of glycosylation at N165 and N234 (Figure 6B) by converting asparagine to alanine significantly reduced binding to ACE2, shifting RBD conformation to a "down" state [97]. Taken together, viral evolution has impacted spike glycosylation, directly modulating spike-ACE2 interactions and promoting immune evasion and greater pathogenicity by sterically masking the polypeptide epitopes [98]. 

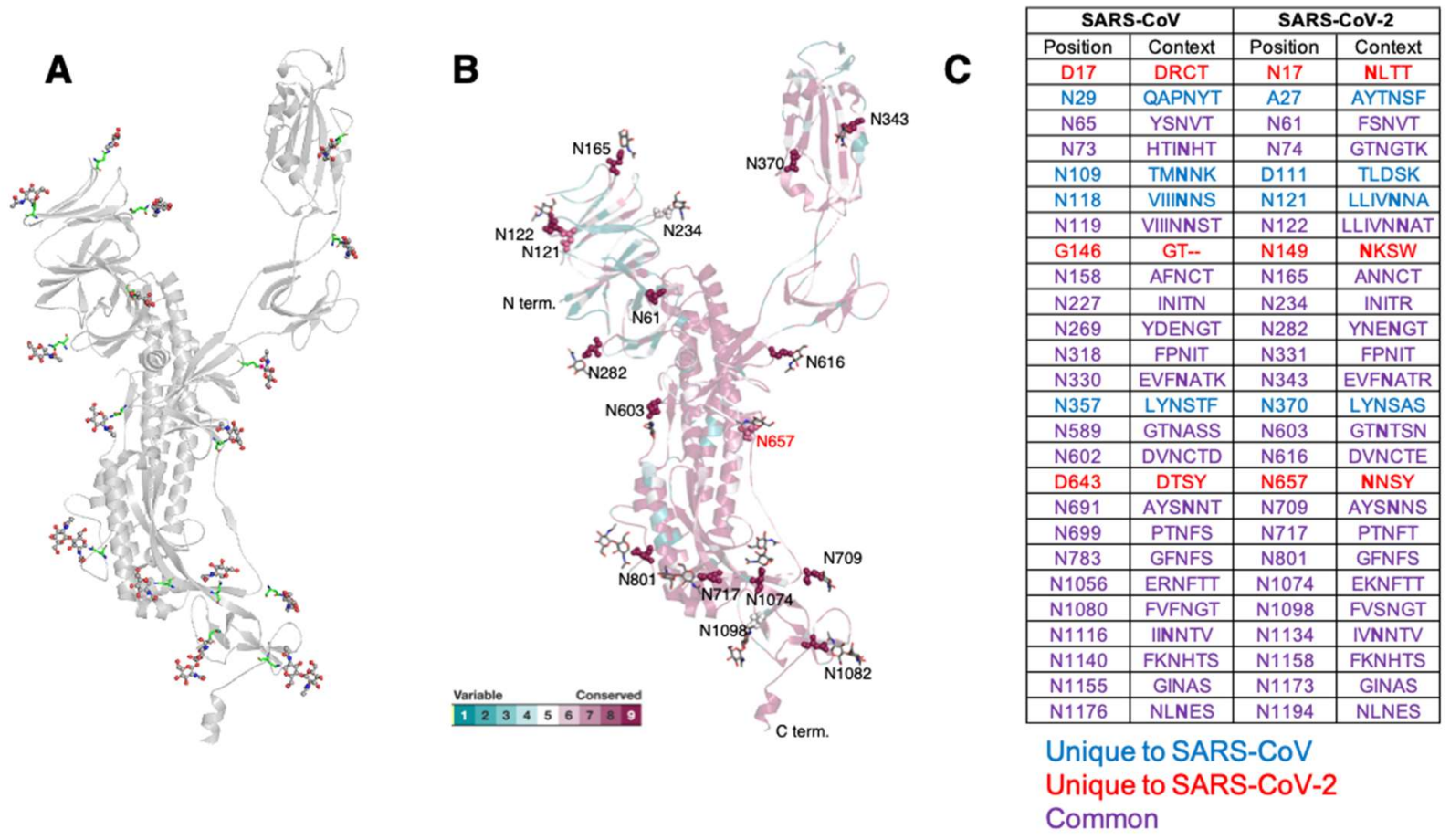

Figure 5: Conservation of glycosylation patterns. (A) All the NAG moieties from the experimentally determined crystal structure are represented in ball-and-sticks with the corresponding $\mathrm{N}$-linked asparagine residues highlighted in green in the monomeric subunit of S protein. (B) The monomeric subunit of S-protein is colored based on the conservation of residues determined through the ConSurf algorithm using default parameters. C) All the corresponding $\mathrm{N}$-linked glycosylation residues between the $\mathrm{S}$ proteins of SARS-CoV and SARS-CoV-2 have been tabulated here.

\section{Molecular diversity of coronavirus host cell receptors and coreceptors}

Host cell receptor molecules are the gateways for the virus into the host cell and hence of utmost clinical importance. Following spike-receptor binding and virus-host membrane fusion, the virus enters the host cell and commences its infection cycle [99, 100]. The literature synthesis analysis was used to identify all the receptors described previously (http://bit.ly/39oLixu). Notable coronavirus receptors include angiotensin-converting enzyme 2 (ACE2) [72, 101-103, 74], dipeptidyl peptidase 4 (DPP4) [103-105], aminopeptidase N (ANPEP/APN/CD13) [103, 106, 107], carcinoembryonic antigenrelated cell adhesion molecule 1 (CEACAM1) [108], C-type lectin L-SIGN (CD209L) [47], Neuropilin-1 [110-112], BSG (CD147/Basigin) [113-115] and sugars [80] (Figure 2B). Additional host receptors ADAM17 (ADAM metallopeptidase domain 17) and GRP78 (also known as heat shock protein family A (Hsp70) member 5 (HSPA5) have also been proposed as possible targets for SARS coronaviruses [116, 117]. 
The cross-genera recognition of the same receptor and intra-genus recognition of different receptors makes the coronavirus receptor recognition code a hard nut to crack. For example, both HCoV-NL63 (from Alphacoronavirus) and SARS-CoV (from Betacoronavirus) recognize ACE2 as their host cell receptor through their S1-CTDs [102]. In contrast, betacoronaviruses SARS-CoV and MERS-CoV use their S1-CTDs to recognize different receptors, ACE2 and DPP4, respectively [74, 105, 118-120]. The cellular entry of SARS-CoV-2 is reported to be mediated by one or more host proteins such as ACE2 [118, 121-125], DPP4 [118, 121, 126], serine protease for spike protein priming (TMPRSS2) [122, 124], and heparin [127]. Expression analyses of these hostreceptors across normal tissues from the GTEx study reveal nearly ubiquitous expression at RNA-level in all the tissues except the brain [128]. Each of these molecules has one or more endogenous roles (described in subsequent sections) and are "hijacked" by the virus to act as its receptor(s).

\section{Angiotensin-converting enzyme 2 (ACE2) is the primary receptor for SARS-CoV and SARS-CoV-2}

One of the most well-studied and well-characterized of all the known coronavirus receptors is ACE2, which is a homolog of the Angiotensin-converting enzyme (ACE). Endogenously, it plays a role in the negative regulation of the Renin-AngiotensinAldosterone System (RAAS) that controls fluid homeostasis and blood pressure [129]. The enzyme ACE converts angiotensin I (Angl) to angiotensin II (Angll), which is the main bioactive angiotensin peptide in RAAS. ACE2 is a zinc-dependent carboxypeptidase that offsets this effect by cleaving Angll to produce the vasodilator, angiotensin(1-7) (Ang 1-7) $[130,131]$. ACE2 downregulation has been implicated in lung failure and injury, and thus a coronavirus-induced reduction in ACE2 expression may expedite lung damage [132134]. Upon the occupancy of ACE2 by SARS-CoV-2, the increased serum level of free Angiotensin II (Ang II) due to a reduction of ACE2-mediated degradation promotes activation of the NF-kappa B pathway via Ang II type 1 receptor (AT1R), followed by interleukin-6 (IL-6) production. 


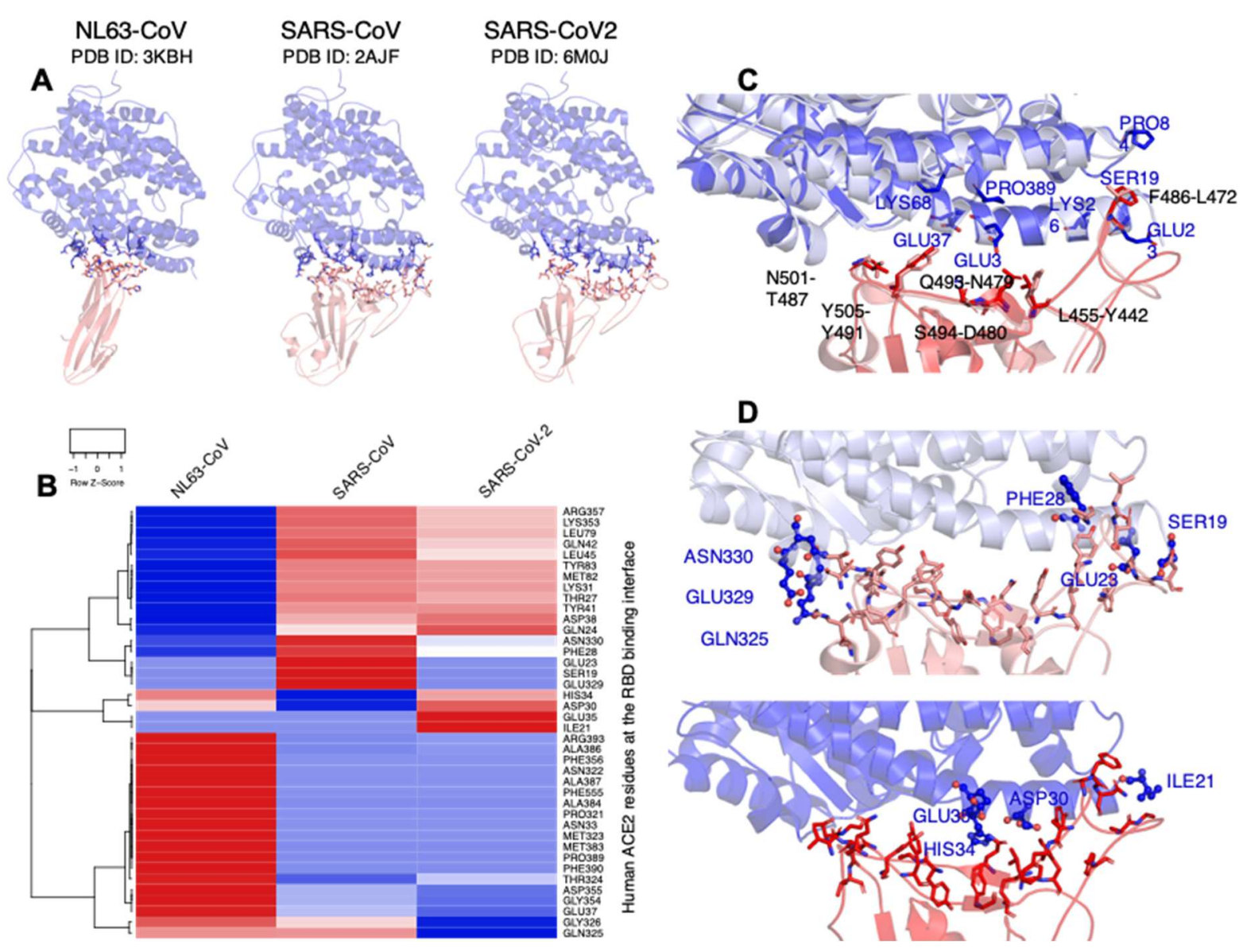

Figure 6: ACE2 receptor interactions. (A) Experimentally determined structural complexes of human ACE2 protein (blue) with the receptor-binding domains of NL63, SARS-CoV, and SARS-CoV-2 receptors have been depicted here. The residues at the interface are depicted in the wireframe. (B) A heatmap showing the calculated solvation energy effect inferred from the buried surface area of interface residues from human ACE2 protein using PDBePISA [135]. (C) The structural superposition of the macromolecule complex comprising human ACE2 (blue) and the receptor-binding domains (red) of SARS-CoV (lighter shade) and SARS-CoV-2 (darker shade). (D) The same structural complexes of human ACE2 and the receptor-binding domains of SARSCoV (above panel) and SARS-CoV-2 (below panel) with the residues from human ACE2 that are differentially contributing to the interaction interface have been highlighted in the wireframe.

ACE2 functions as the receptor for the coronaviruses NL63 [102], SARS-CoV [101] and SARS-CoV-2 [125] (Figure 6A). There are 32 protein-modifying polymorphisms in the ACE2 gene across different human populations, and seven are hotspot variants. [136, 137]. The use of ACE2 as a receptor may have enabled coronaviruses to increase their host range, as ACE2 exhibits a high degree of conservation across various mammalian species. Viruses also require a protease for its activation and they typically hijack the proteases processing the apical membrane proteins. SARS-CoV-2 also utilizes TMPRSS2 as its co-receptor, allowing efficient fusion 
with the membrane and viral entry. In comparison to SARS-CoV, it was found that only six substitution mutations in SARS-CoV-2 RBD (Asn439/Arg426, Leu452/Lys439, Thr470/Asn457, Glu484/Pro470, Gln498/Tyr484, and Asn501/Thr487) was sufficient to enhance binding to human ACE2 [101]. Such variations can explain the higher infectivity of SARS-CoV-2 and the prognosis of COVID-19.

Analysis of experimentally solved structures of RBM complexes in the virus and its partner virus-binding motif (VBM) in the host cell receptor has shed some light on our understanding of this crucial interaction [69, 74, 75, 138-140]. A cryo-EM structure of the SARS-CoV-2 spike protein RBD bound to the ACE2 receptor suggests that an ACE2 dimer binds to two spike proteins [125], whereas the crystal structure of the SARS-CoV spike protein bound to ACE2 reveals binding of monomers [74]. However, the superimposition of these structures shows a root mean square deviation (RMSD) of 0.68 $\AA$ over 139 pairs of $\mathrm{C}_{\alpha}$ atoms [125], suggesting very similar binding modes of these viruses to the ACE2 receptor. According to the literature, the SARS-CoV-2 spike protein has a 10-20 times higher affinity to the ACE2 receptor as compared to that of SARS-CoV [141]. A more in-depth analysis of the interface residues between the human ACE2 and the receptor-binding domains from NL63, SARS-CoV, and SARS-CoV-2 reveals the differential contribution of ACE2 residues towards the interface (Figure 6B). The interface residues in ACE2 that interact with the NL63 RBD of S protein are entirely different from the ACE2 residues interacting with the RBDs of SARS-CoV and SARS-CoV-2, suggesting convergent evolution. On the other hand, while SARS-CoV and SARS-CoV-2 receptor binding domains interact with the same set of residues from ACE2 (Figure 6C), key differences were observed in terms of solvation energy contribution for few residues at the interface. The ACE2 residues His34, Asp30, Glu35, and Ile21 had greater contribution towards the formation of a structural complex with the RBD in SARS-CoV-2, whereas in contrast, higher contributions were observed from Asn330, Phe28, Glu23, Ser19, and Glu329 residues from ACE2 in the SARS-CoV receptor-binding complex structure. Recent data suggests the emergence of new mutations in spike protein with altered binding affinity to ACE2 which will be discussed in the next section.

\section{Novel mutations in spike protein of SARS-CoV-2 emerging variants increase viral transmission and decrease vaccine efficacy}

Multiple SARS-CoV-2 variants have been circulating globally, with several new variants emerging in the fall of 2020. Of these, three variants of prominence include the UK variant (known as 20l/501Y.V1, VOC 202012/01, or B.1.1.7), the South African variant (known as $20 \mathrm{H} / 501$ Y.V2 or B.1.351), and the Brazilian variant (known as 20J/501Y.V3 or P.1) (Figure 7). In total, 18 different mutations and deletions were identified in the UK strain, with the spike protein alone harboring nine of them. The critical spike variants include the N501Y in the RBD domain, 69/70 deletion in the N-terminal domain (leading to a conformational change in the viral spike protein), and $\mathrm{P} 681 \mathrm{H}$ in the vicinity of $\mathrm{S} 1 / \mathrm{S} 2$ furin cleavage site. Evidence suggests that the UK variant may have a $35-45 \%$ higher 
transmission rate and may soon become the most dominant variant in the US by March 2021 [142]. It was speculated that the UK variant may have evolved from prolonged SARS-CoV-2 infection in a single immunocompromised patient [143]. This was demonstrated in the case of a peculiar COVID-19 case from Boston who accumulated more than 20 mutations over a persistent five month infection cycle [144]. Interestingly, the Boston patient shares the key mutations, N501Y and E484K, also reported in the UK and SA variants indicating these mutations may confer a fitness advantage. The South African (SA) variant emerged independently, although it shares the N501Y mutation with the UK strain alongside two other novel key mutations in the spike protein, K417N and E484K. The Brazilian variant has 17 unique mutations including three in the RBD of the virus spike protein. This troubling new variant was first detected in Amazon city of Manaus, Brazil when a startling resurgence of COVID-19 cases were observed. An earlier study had estimated that nearly $76 \%$ had already been infected prior to resurgence, which should have conferred a high level of immunity. This variant appears to possess a unique constellation of lineage-defining mutations, which can potentially be associated with increased transmissibility and propensity for reinfection. Another lineage, B.1.258, carrying both N439K and D614G mutations that emerged in Scotland in March 2020, has been independently spreading in Europe ever since, gaining ground in more than 37 countries. These variants have now been detected in other countries, with the SA variant being already reported in the UK [145] and the UK variant gaining a strong foothold in the US [146]. With the spread of virus, there are now raising concerns that the new variants may have altered sensitivity to antibody neutralization and possibly influence vaccine efficacy. The E484K mutation in the SA variant [147] and N439K mutation in the Scotland strain [148] have reduced binding to both clinical antibodies and convalescent or postvaccination serum samples. Similar studies have shown N501Y variant that is shared by both UK and SA variants to have 3 to 6-fold reduced neutralization by most monoclonal antibodies, convalescent plasma ( $\sim 3$ fold) or vaccine sera $(\sim 2$-fold), while the E484K mutation was considerably more refractory to convalescent plasma ( 11-33 fold) and vaccine sera $(\sim 6 / 5-8 / 6)[149,150]$.

A study on evaluating Moderna's SARS-CoV-2 mRNA-1273 vaccine on the emerging variants indicated that there was six-fold reduction in neutralizing titers for the SA variant in comparison to the UK variant that showed low but significant impact on neutralization [151, 152]. Similarly, preliminary data suggests that the Pfizer COVID-19 vaccine, BNT162b2, may be effective against the UK strain. However, effective neutralization of E484K mutation of the SA variant required higher doses of the vaccine $[153,154]$ (Pfizer Press Release). Notably, in an in vitro study, E484K emerged as one of the escape mutations following serial passages of SARS-CoV-2 through convalescent sera, along with a deletion and insertion in NTD loops, that completely abrogated virus neutralizing activity [155]. These emerging variants that can propagate across populations and time warrants the need for constant molecular surveillance. It is also possible that the currently available vaccines will need to be modified in order to generate equally strong antibody responses against these emerging variants. 


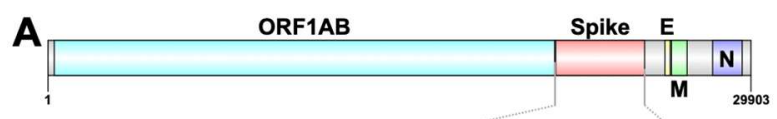

B
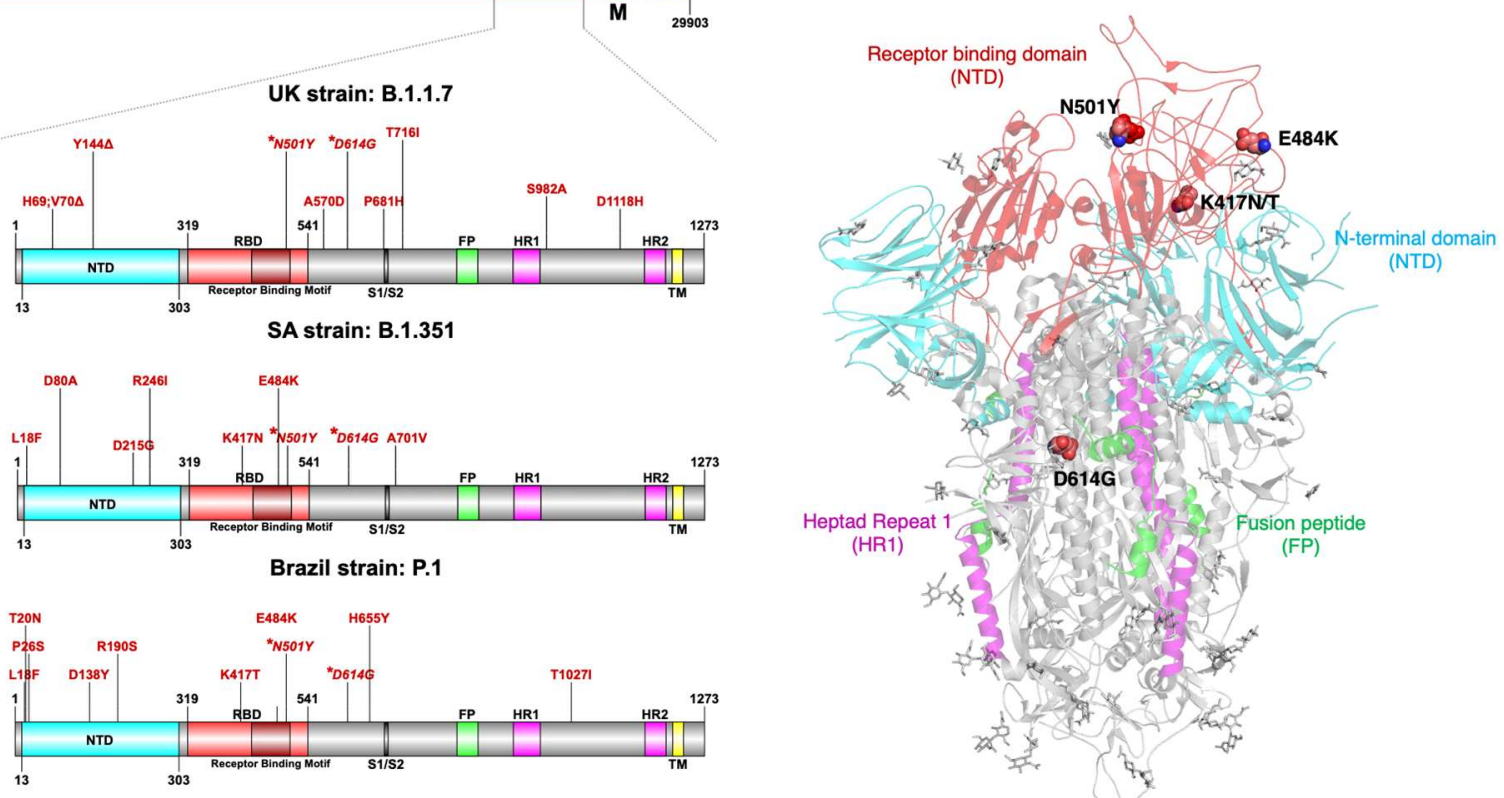

Figure 7: Novel mutations in spike protein. (A) The graphical representation of genome organization of SARS-CoV-2. The different spike protein mutations observed in the emerging strains of SARS-CoV-2 in UK, SA and Brazil have been highlighted in the context of different domains in spike proteins. (B) Cartoon representation of homotrimeric spike protein colored based on the domain organization depicted in (A). The mutations in the receptor binding domain of the spike protein reported to contribute towards the fitness and pathogenicity of the virus are represented as spheres.

\section{Exploring the role of immunogenic $T$ and $B$ cell epitopes for peptide vaccine development}

Conventional vaccines such as recombinantly expressed viral proteins, inactivated viruses or mRNA vaccines can cause autoimmune and allergic reactions, are easily degraded, and require freezing cold storage and transport facilities. Peptide vaccine strategies, on the other hand, can overcome several of these disadvantages [156]. Ideally, peptide vaccines should contain epitope regions optimized for simultaneous activation of B cells, CD4+ T cells, and cytotoxic CD8+ T cells to drive both the humoral and cellular arms of the adaptive immune system with high specificity. With this in mind, researchers are looking at immunogenic regions in SARS-CoV-2 and other coronaviruses, that are distributed across structural proteins such as spike, nucleocapsid, envelope, and membrane proteins [156]. The Immune Epitope Database (IEDB; https://www.iedb.org/; 17 Feb 2020) reports close to 2228 linear T and B cell epitopes, with positive experimental assays, of SARS-CoV-2 in human hosts. Immumodominant Tcell epitopes that recognize multiple structural regions of SARS-CoV-2, including spike and nucleocapsid protein, have been detected in patients recovering from COVID-19 and in unexposed individuals [157-159]. These studies indicate the presence of robust, long 
lasting and pre-existing $\mathrm{T}$ cell immunity to SARS-CoV-2 in the general population, possibly contributed by multiple "public" T cell receptor (TCR) sequences recognizing peptides from other common-cold coronaviruses, Human cytomegalovirus (HCMV), human herpes virus-5 (HHV-5) and influenza A virus [157, 160, 161]. This suggests that exposure to other viruses may confer protection against COVID-19 through cross-reactive T-cells. Several immune-informatics and experimental studies have also predicted putative $\mathrm{T}$ and $\mathrm{B}$ cell epitopes that could serve as promising targets for peptide-based vaccine development [162-166]. Presently, only a handful of these peptide vaccines are in various stages of preclinical trials, such as the pan coronavirus vaccine from Valo Therapeutics that uses a novel Peptide-coated Conditionally Replicating Adenovirus (PeptiCRAd) technology, FlowVax-COVID19 from Flow pharma, DPX-COVID19 from IVM Inc., and li-key from Generex [165]. Still, none of them have been approved for clinical use.

\section{Molecular diversity of other host cell receptors and coreceptors}

The primary SARS-CoV and SARS-CoV-2 receptor, ACE2, is expressed in various human tissues, including the lung, liver, stomach, ileum, colon, and kidney [167]. The expression levels are relatively low in the alveolar type II (AT2 cell) of the lung, which is the target cell for SARS-CoV-2 [167]. Based on the co-expression analyses, it has been hypothesized that SARS-CoV-2 infection may be facilitated by the use of co-receptors (auxiliary membrane proteins) along with the primary ACE2 receptor [168]. Membrane proteins exhibiting the most similar expression to ACE2 across various human tissues can act as its putative co-receptors. Many of these ACE2 co-expressing proteins are peptidases, including APN, DPP4, and ENPEP [168], of which APN [121, 169] and DPP4 $[104,105]$ have been previously shown to be human coronavirus receptors. The TMPRSS2 protease has also been implicated in priming SARS-CoV-2 for infection [170]. In this section, we will elaborate on other known receptors and co-receptors for coronavirus infection.

\section{Dipeptidyl peptidase 4 (DPP4, CD26): receptor for MERS-CoV and coreceptor for SARS-CoV-2}

DPP4 is a transmembrane exoprotease cleaving at the amino-terminal of substrates with a preference for proline, hydroxyproline, or alanine in the penultimate position. DPP4 plays a prominent role in maintaining glucose homeostasis by the inactivation of incretin hormones glucose-dependent insulinotropic polypeptide (GIP) and glucagon-like peptide-1 (GLP-1), due to which DPP4 inhibition is a therapeutic strategy for the management of type 2 diabetes [171]. DPP4 plays various roles in immune processes like activating or inactivating several chemokines including IP-10, I-TAC, and 
RANTES, activating lymphocyte proliferation, and suppressing cytokine production and T cell activation through its interaction with adenosine deaminase (ADA) $[77,78]$.

DPP4 was identified as a receptor for the MERS-CoV, but recent reports suggest that SARS-CoV-2 also uses DPP4 as a coreceptor along with ACE2 [42]. Fifteen residues in DPP4 interact with the MERS coronavirus spike protein. Analysis of naturally occurring polymorphisms in DPP4 revealed that four polymorphisms K267E, K267N, A291P, and $\Delta 346-348)$ reduced viral infection. It was found that K267E, K267N, A291P affected binding of DPP4 with spike protein while $\Delta 346-348$ caused a defect in receptor transport. These polymorphisms, however, occur at very low frequencies in the population [172].

\section{Aminopeptidase N (APN, ANPEP, CD13): receptor for HCoV- 229E}

APN metabolizes a wide range of physiological peptides, including neuropeptides that affect pain and mood regulation, as well as vasoconstrictive peptides that regulate blood pressure. Apart from its function as an aminopeptidase, APN also plays a role in cell adhesion and motility, tumor migration, and angiogenesis [173, 173, 174]. Alphacoronaviruses, including HCoV-229E, porcine transmissible gastroenteritis virus (TGEV), and feline infectious peritonitis virus (FIPV), are known to bind to the APN receptor via the RBD located in the CTD of the spike protein. Notably, residues 132-295 were found to be essential for receptor function and a stretch of only 8 amino acids in a hypervariable region was sufficient to convert porcine APN to receptor enabling HCoV $229 \mathrm{E}$ entry underscoring the importance of changes that extended the host range of these viruses [175]. The patients with Parkinson's disease (PD) appear to be susceptible to worse outcomes from COVID-19. It is speculated that overexpression of ANP in these patients could be one of the causes for it $[176,177]$.

\section{Carcinoembryonic antigen-related cell adhesion molecule 1 (CEACAM1): a receptor for MHV}

CEACAM1,the prototype receptor of betacoronavirus murine hepatitis virus (MHV), is usually involved in cell-cell adhesion and immune modulation. Unlike other coronavirus receptors, CEACAM1 binds to the NTD of the MHV spike protein, where it functions as a lectin [78]. The lectin function at the $\mathrm{N}$ terminus of the spike is important from an evolutionary standpoint in that it enabled the ancestral coronavirus to bind to carbohydrate moieties, expanding its tropism and infectivity to humans $[78,178]$. The fusogenic activity and conformational changes to spike protein are triggered by the $\mathrm{N}$ terminal domain of CEACAM1 [108]. One of the unique features of the MHV, JHM strain is its ability to spread independently of the CEACAM1 receptor, as demonstrated in CEACAM1-deficient mice models [179, 180]. 


\section{DC-SIGN (CD209) and L-SIGN (CD209L): receptors for HCoV- 229E, SARS-CoV and SARS-CoV-2}

C-type lectins dendritic cell-specific intercellular adhesion molecule-3-grabbing nonintegrin (DC-SIGN) and the closely related liver/lymph node-specific intracellular adhesion molecule-3-grabbing non-integrin (L-SIGN) are cell membrane glycoproteins. DC-SIGN receptor has already been reported to be involved in the dendritic cell-mediated transmission of other viruses such as HIV, dengue, and CMV as well. The heterologous expression of human L-SIGN through retroviral vectors in Chinese hamster ovary cells rendered them susceptible to both SARS-CoV and HCoV-229E infection [109, 181]. Recently both these proteins have also been reported to be important for the entry of the SARS-CoV-2 virus into the host cell [182].

\section{Neuropilin-1 (NRP1): a secondary receptor for SARS-CoV-2}

NRP1 is a transmembrane glycoprotein cell surface receptor that plays a major role in angiogenesis, lymphangiogenesis, neural and cardiovascular development [183]. NRPs (Neuropilin-1 and Neuropilin-2) are known to interact with various extracellular signaling proteins such as vascular endothelial growth factor (VEGF) isoforms, class 3 semaphorins, and transforming growth factor beta (TGF $\beta$ ) $[184,185]$ that triggers various downstream signalling cascades. Recently, NRP1 and its homolog Neuropilin-2 (NRP2) were also identified to interact with SARS-CoV-2 spike-protein [112]. Moreover, through autopsies of COVID-19 positive patients, SARS-CoV-2 is reported to infect NRP1 positive olfactory epithelial cells [110]. The presence of the distinctive furin cleavage site (679NSPRRAR-685) in the SARS-CoV-2 spike protein is shown to enhance its association with the NRP proteins. This feature is a structural overlap observed across the host binding partners of NRPs and the SARS-CoV-2 spike protein, as the NRPs specifically bind to proteins agreeing to $\mathrm{C}$-end Rule (CendR) peptide motifs. Markedly, to date, this protein was not reported as receptors to any other coronaviruses. The SARS-CoV-2 virus uses the spike protein receptor binding domain to exploit the receptor-ligand interaction network of the host and this potentially may have enhanced its infectivity and diversified the tissue tropism.

\section{BSG (CD147, Basigin, extracellular matrix metalloproteinase inducer (EMMPRIN)): a secondary receptor for SARS-CoV and SARS-CoV-2}

CD147, earlier identified as one of the host cell receptors for SARS-CoV, is now reported to perform a similar function to assist SARS-CoV-2 cell invasion [113, 186]. Some of the compelling observations that relate CD147 to coronavirus infections is the expansion of its expression pattern from basolateral to apical membrane in kidney samples of COVID19 positive patients [187] and susceptibility of BHK (Baby Hamster Kidney) cells 
expressing human CD147 towards SARS-CoV-2 infection [113]. CD147 is present in lung cells [116], RBCs [188] and it is highly expressed in activated T-lymphocytes [127, 128] and macrophages [191]. One of the manifestations of severe COVID-19 is lymphopenia, i.e., low lymphocyte counts [192]. As ACE2 is expressed in very low amounts in T lymphocytes [193, 194], CD147 may provide a possible new alternate route for viral infection in T cells. Hence, CD147 is being explored as one of the potential targets for COVID-19 treatment, vis-a-vis Azithromycin with some known antiviral activity mediated by CD147 [114].

\section{What unifies the different coronavirus receptors?}

\section{Distinct pattern of coexpression observed across different coronavirus receptors}

Detailed knowledge of the expression and regulation patterns of the coronavirus receptors required for the viral entry will enable us to devise effective therapies. In order to investigate the common thread that unifies all the coronavirus receptors, we investigated their co-expression and interaction patterns. Remarkably, ACE2 is highly coexpressed with CEACAM1 and DPP4 with other peptidase receptors, such as ANPEP and ENPEP. Further, cellular proteases like TMPRSS2, FURIN, and CathepsinL, which act as critical factors for spike activation, fusion, and entry [195], are coexpressed with the coronavirus receptors DPP4, CEACAM1, and ANPEP. Single-cell expression analysis of several SARS-CoV-2 and coronavirus-associated receptors and proteases in multiple healthy human tissues revealed co-expression was highest in intestinal and airway goblet cells, enterocytes, and kidneys [196]. A positive correlation was also seen between promoter methylation patterns in TMPRSS2 and ACE2 using bisulfite conversion and qMS (quantitative methylation-specific) PCR on the saliva of COVID-19 patients following infection, indicating that their expression is also strongly linked and influenced by epigenetic modifications [197]. Interestingly, DPP4 and ANPEP are co-localized in cortical neurons and involved in ischemia-related inflammation [198]. Additionally, both the receptors and proteases are strongly co-expressed in the same tissues, facilitating their coordinated action, such as in the upper and lower airways (bronchi), respiratory tract, and lungs [199]. NRP1, the recently identified SARS-CoV-2 receptor, is coexpressed with ANPEP and is also highly expressed in the respiratory and olfactory epithelium, with the highest expression in endothelial and epithelial cells [112].

\section{Coronavirus receptors show evolutionary conservation}

Another unifying factor among the coronavirus receptors is the high degree of conservation observed in membrane ectopeptidases (ACE2, DPP4, and APN) across many animal species [103]. The broad host range of SARS-CoV-2 is ascribed mainly to ACE2 being highly conserved across several vertebrates and mammalian species 
revealed by comparative genomics and structural analysis [200]. Such conservation, especially in the virus-receptor binding interface, may have been evolutionarily selected by the virus to enable their usage in different host species and permit zoonotic transmissions.

\section{Binding affinity dictates infectivity of the virus}

Studies have shown that the binding affinity of the viral spike protein RBD with the host ACE2 regulates its pathogenicity, infectivity, and host range. Both SARS-CoV and NL63 bind ACE2, but SARS-CoV causes severe respiratory disease while NL63 frequently causes only a mild respiratory infection. This difference in pathological consequences has been partly ascribed to the lower binding affinity of NL63 spike to ACE2 compared to SARS-CoV, Bat-SARSr-CoV, RaTG13, that resulted in a tighter ACE2-RBD binding. This may have possibly precipitated the bat-to-human transmission and highly transmissible SARS-CoV-2 with a devastating outcome. Earlier in the year, the D614G spike variant was identified in Italy to be ten times more contagious than the original Wuhan strain, responsible for the rapid spread of SARS-CoV-2 in Europe [201]. Although this residue is outside the RBD, the substitution alters a hydrogen-bond interaction with T859 of a neighboring spike in the trimer, which shifts the RBD to an 'up' conformation, enhancing binding with the ACE2, leading to higher viral infectivity [202]. Preliminary genomic characterization of the emerging B.1.1.7 SARS-CoV-2 strain in the UK that is currently found to be spreading $70 \%$ faster than the older strain, shows this variant carries a mutation in one of the six key residues within the RBD, namely N501Y, which increases its binding affinity to human and murine ACE2. Apart from this, it has a deletion in spike 69-70 that has implications in immune evasion, and $\mathrm{P} 681 \mathrm{H}$ mutation that is adjacent to the Furin cleavage site (COVID-19 Genomics Consortium UK (CoG-UK; https://www.cogconsortium.uk).

\section{Common pathways used by coronaviruses for host cell entry are poorly understood}

The cellular host signaling pathways that underlie the mechanisms of coronavirus infection have been poorly elucidated. Identifying the common pathways impacted by coronavirus infection may help to shed more light on the coronavirus pathophysiology and modes of transmission. It has been shown that coronaviruses can enter host cells through a pH-dependent endocytic pathway involving either cellular receptors, sugars, or lipid rafts via clathrin- and caveolae-independent mechanism, which is consistent with their broad cellular tropism [196]. Additionally, neuropilins, like NRP1, are known to mediate an endocytic pathway resembling macropinocytosis through the internalization of CendR ligands [203]. Both SARS and MERS diseases involve acute respiratory distress, gastrointestinal disorders, and cardiovascular complications. In silico experiments suggest DPP4, previously established as a receptor for MERS, may also 
bind SARS-CoV-2 [204]. Both ACE2, a component of the renin-angiotensin-aldosterone system (RAAS) and DPP4 are overexpressed in diabetes and cardiovascular disease, which are considered as high risk factors for severe COVID-19 [118]. Due to their synergistic effect, a combined inhibition of ACE2 and DPP4 has been suggested as a potential therapeutic strategy to combat this virus [205]. NRP1, along with its co-receptor VEGFR2 is also involved in regulating cardiovascular function and angiogenesis. Although the mechanistic details are still being evaluated, severe COVID19-associated vascular pathologies may be mediated through common pathways involving these receptors.

\section{Conclusions and future directions}

One of the critical steps in the viral infection cycle is recognizing receptors on the host cell membrane. How a virus selects a particular molecule to be its receptor amidst a host of other molecules on the cell surface remains one of the crucial unanswered questions in virology. These receptors can aid in the attachment of the virus to the host cell surface along with its uncoating and internalization into the host cell. Based on this, one can infer common characteristics of the receptors: possessing a VBM, ability to promote conformational change, and potential to interact with molecules in the signaling cascade. However, to broaden their host range and to effectively carry out cross-species transmission, viruses might 'opt' for receptor molecules that are more conserved in evolution, at least in their VBMs. However, this also exposes their vulnerability in their choice of highly conserved peptidases that can be exploited for a combined coronavirus therapeutic intervention strategies.

Notably, the viruses may also select receptors that are co-expressed and colocalized with the proteases that are needed to cleave and activate viral fusion and entry into the host cells. Hijacking the host's internal protease machinery to its advantage also exposes an Achilles heel, wherein the use of specific protease inhibitors such as camostat mesylate, which is active against TMPRSS2, can be used as the first line of defense against the virus.

As compared to influenza or polioviruses, the coronaviruses have evolved to recognize a broader range of host cell receptors. The influenza virus recognizes glycans (terminating in a2,3-linked sialic acid for strains affecting birds and in a2,6-linked sialic acid for those affecting humans) [168]. In contrast, polioviruses gain entry into their host cell via the Poliovirus Receptor (PVR) [207]. The diverse nature of molecules selected by the coronaviruses to infect the host cell along with its ability to recombine and shift hosts makes it a long-term threat to human health. Moreover, its ability to jump host species poses a constant threat of generating more contagious strains. Hence, developing vaccines [208] or small-molecule drugs [209] against the conserved structural elements of the SARS-CoV-2 genome (at the level of genomic RNA, as well as translated structural proteins) remains our best bet to curb the ongoing pandemic. 
Like many other viruses, coronaviruses can mutate (although at a lower rate in comparison to other RNA viruses such as flu and HIV) and give rise to variants. Since the virus is contagious and can easily spread, the variants with higher fitness landscape can get fixed in the viral population giving rise to emergent strains and thus pose a recurring threat to human health. Their ability to cause rapid human-to-human transmissions has led to periodic pandemics in recent decades. The increasing binding affinity of the RBD of the virus for the coronavirus receptors has also evolved a higher capacity for pathogenicity and rapid spread. The use of antagonists to coronavirus receptors, such as recombinant human ACE2 (rhACE2) in human trials (APN01-COVID-19, NCT04335136), is being explored. Such a rhACE2 would not only prevent SARS-CoV-2 entry but also possibly protect from lung injury and vascular dysfunction [118]. Taken together, although coronavirus receptors encompass a rather diverse group with broad specificity and distinct pathogenicity, the SARS-CoV-2 pandemic marks a historic turning point that has led to our accelerated understanding of these viruses and improved and novel strategies to effectively target them.

Table 1: Observed variants and their associated frequency at the furin cleavage site in spike protein. The GISAID spike protein sequence dataset dated 29 December 2020 was used for this analysis. Amino acid position distinct from the highly conserved "RRARSVAS" motif is highlighted in bold letters.

\begin{tabular}{cc}
\hline Sequence variants at the furin cleavage site & Total number of sequences \\
\hline RRARSVAS & 260692 \\
\hline RRARSVVS & 945 \\
\hline RRARSLAS & 260 \\
\hline RRVRSVAS & 107 \\
\hline RRARSVSS & 55 \\
\hline RRARSVAI & 54 \\
\hline RRARSVAR & 20 \\
\hline RRARSIAS & 16 \\
\hline Other variants with < 10 occurrences & 63 \\
\hline
\end{tabular}

\section{Declarations}

\section{Ethics approval and consent to participate}

Not applicable.

\section{Consent for publication}

All the authors give their consent for the publication of the manuscript. 


\section{Availability of data and material}

Not applicable.

\section{Competing interests}

All the authors are affiliated with nference and have a financial interest in the company.

\section{Funding}

No external funding was received for this work.

\section{Authors' contributions}

P.G. wrote the first draft; P.A. generated the figures; all other authors have contributed to the writing of subsequent drafts of the manuscript. All authors have read and approved the final version of this manuscript.

\section{Acknowledgements}

The authors acknowledge the contribution of members of nference for their suggestions on improving the manuscript.

\section{References}

1. Enjuanes L, Almazán F, Sola I, Zuñiga S (2006) Biochemical Aspects of Coronavirus Replication and Virus-Host Interaction. Annu Rev Microbiol 60:211230. https://doi.org/10.1146/annurev.micro.60.080805.142157

2. Perlman S, Netland J (2009) Coronaviruses post-SARS: update on replication and pathogenesis. Nat Rev Microbiol 7:439-450. https://doi.org/10.1038/nrmicro2147

3. Li F (2016) Structure, Function, and Evolution of Coronavirus Spike Proteins. Annu Rev Virol 3:237-261. https://doi.org/10.1146/annurev-virology-110615-042301

4. Wu A, Peng Y, Huang B, et al (2020) Genome Composition and Divergence of the Novel Coronavirus (2019-nCoV) Originating in China. Cell Host Microbe 27:325328. https://doi.org/10.1016/j.chom.2020.02.001

5. Decaro N, Lorusso A (2020) Novel human coronavirus (SARS-CoV-2): A lesson from animal coronaviruses. Vet Microbiol 244:108693. https://doi.org/10.1016/j.vetmic.2020.108693

6. Nakagawa S, Miyazawa T (2020) Genome evolution of SARS-CoV-2 and its virological characteristics. Inflamm Regen 40:17. https://doi.org/10.1186/s41232020-00126-7

7. Nakagawa K, Lokugamage KG, Makino S (2016) Viral and Cellular mRNA Translation in Coronavirus-Infected Cells. Adv Virus Res 96:165-192. https://doi.org/10.1016/bs.aivir.2016.08.001 
8. Chen Y, Tao J, Sun Y, et al (2013) Structure-Function Analysis of Severe Acute Respiratory Syndrome Coronavirus RNA Cap Guanine-N7-Methyltransferase. J Virol 87:6296-6305. https://doi.org/10.1128/JVI.00061-13

9. Coronaviridae - Positive Sense RNA Viruses - Positive Sense RNA Viruses (2011). In: Int. Comm. Taxon. Viruses ICTV. https://talk.ictvonline.org/ictvreports/ictv_9th_report/positive-sense-rna-viruses2011/w/posrna_viruses/222/coronaviridae. Accessed 6 Nov 2020

10. Tang $Q$, Song $Y$, Shi $M$, et al (2015) Inferring the hosts of coronavirus using dual statistical models based on nucleotide composition. Sci Rep 5:17155. https://doi.org/10.1038/srep17155

11. Lorusso A, Calistri P, Petrini A, et al (2020) Novel coronavirus (SARS-CoV-2) epidemic: a veterinary perspective. Vet Ital 56:5-10. https://doi.org/10.12834/Vetlt.2173.11599.1

12. Gorbalenya AE, Baker SC, Baric RS, et al (2020) The species Severe acute respiratory syndrome-related coronavirus : classifying 2019-nCoV and naming it SARS-CoV-2. Nat Microbiol 5:536-544. https://doi.org/10.1038/s41564-020-0695-z

13. Zhu N, Zhang D, Wang W, et al (2020) A Novel Coronavirus from Patients with Pneumonia in China, 2019. N Engl J Med 382:727-733.

https://doi.org/10.1056/NEJMoa2001017

14. Huang C, Wang Y, Li X, et al (2020) Clinical features of patients infected with 2019 novel coronavirus in Wuhan, China. Lancet Lond Engl 395:497-506. https://doi.org/10.1016/S0140-6736(20)30183-5

15. Zhou P, Yang X-L, Wang X-G, et al (2020) Discovery of a novel coronavirus associated with the recent pneumonia outbreak in humans and its potential bat origin. bioRxiv 2020.01.22.914952. https://doi.org/10.1101/2020.01.22.914952

16. Drexler JF, Gloza-Rausch F, Glende J, et al (2010) Genomic Characterization of Severe Acute Respiratory Syndrome-Related Coronavirus in European Bats and Classification of Coronaviruses Based on Partial RNA-Dependent RNA Polymerase Gene Sequences. J Virol 84:11336-11349. https://doi.org/10.1128/JVI.00650-10

17. Drosten C, Günther S, Preiser W, et al (2003) Identification of a novel coronavirus in patients with severe acute respiratory syndrome. $\mathrm{N}$ Engl J Med 348:1967-1976. https://doi.org/10.1056/NEJMoa030747

18. Corman VM, Muth D, Niemeyer D, Drosten C (2018) Chapter Eight - Hosts and Sources of Endemic Human Coronaviruses. In: Kielian M, Mettenleiter TC, Roossinck MJ (eds) Advances in Virus Research. Academic Press, pp 163-188

19. Menachery VD, Yount BL, Debbink K, et al (2015) A SARS-like cluster of circulating bat coronaviruses shows potential for human emergence. Nat Med 21:1508-1513. https://doi.org/10.1038/nm.3985

20. Menachery VD, Yount BL, Sims AC, et al (2016) SARS-like WIV1-CoV poised for human emergence. Proc Natl Acad Sci U S A 113:3048-3053. https://doi.org/10.1073/pnas.1517719113

21. Wang N, Li S-Y, Yang X-L, et al (2018) Serological Evidence of Bat SARSRelated Coronavirus Infection in Humans, China. Virol Sin 33:104-107. https://doi.org/10.1007/s12250-018-0012-7

22. Edwards CE, Yount BL, Graham RL, et al (2020) Swine acute diarrhea syndrome coronavirus replication in primary human cells reveals potential susceptibility to 
infection. Proc Natl Acad Sci U S A 117:26915-26925.

https://doi.org/10.1073/pnas.2001046117

23. Wagner T, Awasthi S, Wittenberg G, et al (2020) Real-time biomedical knowledge synthesis of the exponentially growing world wide web using unsupervised neural networks. bioRxiv 2020.04.03.020602. https://doi.org/10.1101/2020.04.03.020602

24. Brian DA, Baric RS (2005) Coronavirus Genome Structure and Replication. Coronavirus Replication Reverse Genet 287:1-30. https://doi.org/10.1007/3-54026765-4_1

25. Zeng Q, Langereis MA, van Vliet ALW, et al (2008) Structure of coronavirus hemagglutinin-esterase offers insight into corona and influenza virus evolution. Proc Natl Acad Sci U S A 105:9065-9069. https://doi.org/10.1073/pnas.0800502105

26. Masters PS (2006) The Molecular Biology of Coronaviruses. Adv Virus Res 66:193-292. https://doi.org/10.1016/S0065-3527(06)66005-3

27. Shereen MA, Khan S, Kazmi A, et al (2020) COVID-19 infection: Origin, transmission, and characteristics of human coronaviruses. J Adv Res 24:91-98. https://doi.org/10.1016/j.jare.2020.03.005

28. V'kovski P, Kratzel A, Steiner S, et al (2020) Coronavirus biology and replication: implications for SARS-CoV-2. Nat Rev Microbiol 1-16. https://doi.org/10.1038/s41579-020-00468-6

29. Kumar S, Nyodu R, Maurya VK, Saxena SK (2020) Morphology, Genome Organization, Replication, and Pathogenesis of Severe Acute Respiratory Syndrome Coronavirus 2 (SARS-CoV-2). In: Saxena SK (ed) Coronavirus Disease 2019 (COVID-19): Epidemiology, Pathogenesis, Diagnosis, and Therapeutics. Springer, Singapore, pp 23-31

30. Seong M-W, Kim SY, Corman VM, et al (2016) Microevolution of OutbreakAssociated Middle East Respiratory Syndrome Coronavirus, South Korea, 2015. Emerg Infect Dis 22:327-330. https://doi.org/10.3201/eid2202.151700

31. Krishnamoorthy S, Swain B, Verma RS, Gunthe SS (2020) SARS-CoV, MERSCoV, and 2019-nCoV viruses: an overview of origin, evolution, and genetic variations. Virusdisease 1-13. https://doi.org/10.1007/s13337-020-00632-9

32. Dudas G, Carvalho LM, Rambaut A, Bedford T (2018) MERS-CoV spillover at the camel-human interface. eLife 7:. https://doi.org/10.7554/eLife.31257

33. Mori M, Capasso C, Carta F, et al (2020) A deadly spillover: SARS-CoV-2 outbreak. Expert Opin Ther Pat 30:481-485. https://doi.org/10.1080/13543776.2020.1760838

34. Jaimes JA, André NM, Chappie JS, et al (2020) Phylogenetic Analysis and Structural Modeling of SARS-CoV-2 Spike Protein Reveals an Evolutionary Distinct and Proteolytically Sensitive Activation Loop. J Mol Biol 432:3309-3325. https://doi.org/10.1016/j.jmb.2020.04.009

35. Han G-Z (2020) Pangolins Harbor SARS-CoV-2-Related Coronaviruses. Trends Microbiol 28:515-517. https://doi.org/10.1016/j.tim.2020.04.001

36. Boni MF, Lemey P, Jiang X, et al (2020) Evolutionary origins of the SARS-CoV-2 sarbecovirus lineage responsible for the COVID-19 pandemic. Nat Microbiol 5:1408-1417. https://doi.org/10.1038/s41564-020-0771-4

37. Lam TT-Y, Jia N, Zhang Y-W, et al (2020) Identifying SARS-CoV-2-related 
coronaviruses in Malayan pangolins. Nature 583:282-285.

https://doi.org/10.1038/s41586-020-2169-0

38. Mathavarajah S, Dellaire G (2020) Lions, tigers and kittens too: ACE2 and susceptibility to COVID-19. Evol Med Public Health 2020:109-113.

https://doi.org/10.1093/emph/eoaa021

39. Oude Munnink BB, Sikkema RS, Nieuwenhuijse DF, et al (2021) Transmission of SARS-CoV-2 on mink farms between humans and mink and back to humans.

Science 371:172-177. https://doi.org/10.1126/science.abe5901

40. Sit THC, Brackman CJ, Ip SM, et al (2020) Infection of dogs with SARS-CoV-2. Nature 586:776-778. https://doi.org/10.1038/s41586-020-2334-5

41. Zhou P, Shi Z-L (2021) SARS-CoV-2 spillover events. Science 371:120-122. https://doi.org/10.1126/science.abf6097

42. Shi J, Wen Z, Zhong G, et al (2020) Susceptibility of ferrets, cats, dogs, and other domesticated animals to SARS-coronavirus 2. Science 368:1016-1020. https://doi.org/10.1126/science.abb7015

43. Richard M, Kok A, de Meulder D, et al (2020) SARS-CoV-2 is transmitted via contact and via the air between ferrets. Nat Commun 11:3496. https://doi.org/10.1038/s41467-020-17367-2

44. Sia SF, Yan L-M, Chin AWH, et al (2020) Pathogenesis and transmission of SARS-CoV-2 in golden hamsters. Nature 583:834-838.

https://doi.org/10.1038/s41586-020-2342-5

45. Chan JF-W, Zhang AJ, Yuan S, et al (2020) Simulation of the Clinical and Pathological Manifestations of Coronavirus Disease 2019 (COVID-19) in a Golden Syrian Hamster Model: Implications for Disease Pathogenesis and Transmissibility. Clin Infect Dis Off Publ Infect Dis Soc Am 71:2428-2446. https://doi.org/10.1093/cid/ciaa325

46. Kreye J, Reincke SM, Kornau H-C, et al (2020) A SARS-CoV-2 neutralizing antibody protects from lung pathology in a COVID-19 hamster model. BioRxiv Prepr Serv Biol. https://doi.org/10.1101/2020.08.15.252320

47. Katoh K, Standley DM (2013) MAFFT multiple sequence alignment software version 7: improvements in performance and usability. Mol Biol Evol 30:772-780. https://doi.org/10.1093/molbev/mst010

48. Li F (2008) Structural analysis of major species barriers between humans and palm civets for severe acute respiratory syndrome coronavirus infections. J Virol 82:6984-6991. https://doi.org/10.1128/JVI.00442-08

49. Li F (2013) Receptor recognition and cross-species infections of SARS coronavirus. Antiviral Res 100:246-254.

https://doi.org/10.1016/j.antiviral.2013.08.014

50. Wrobel AG, Benton DJ, Xu P, et al (2021) Structure and binding properties of Pangolin-CoV spike glycoprotein inform the evolution of SARS-CoV-2. Nat Commun 12:837. https://doi.org/10.1038/s41467-021-21006-9

51. Reusken CB, Raj VS, Koopmans MP, Haagmans BL (2016) Cross host transmission in the emergence of MERS coronavirus. Curr Opin Virol 16:55-62. https://doi.org/10.1016/j.coviro.2016.01.004

52. Walls AC, Tortorici MA, Bosch B-J, et al (2016) Cryo-electron microscopy structure of a coronavirus spike glycoprotein trimer. Nature 531:114-117. 
https://doi.org/10.1038/nature16988

53. Kirchdoerfer RN, Cottrell CA, Wang N, et al (2016) Pre-fusion structure of a human coronavirus spike protein. Nature 531:118-121. https://doi.org/10.1038/nature17200

54. Walls AC, Xiong X, Park Y-J, et al (2019) Unexpected Receptor Functional Mimicry Elucidates Activation of Coronavirus Fusion. Cell 176:1026-1039.e15. https://doi.org/10.1016/j.cell.2018.12.028

55. Wu Y, Zhao S (2020) Furin cleavage sites naturally occur in coronaviruses. Stem Cell Res 50:102115. https://doi.org/10.1016/j.scr.2020.102115

56. de Haan C a. M, Haijema BJ, Schellen P, et al (2008) Cleavage of group 1 coronavirus spike proteins: how furin cleavage is traded off against heparan sulfate binding upon cell culture adaptation. J Virol 82:6078-6083. https://doi.org/10.1128/JVI.00074-08

57. Braun E, Sauter D (2019) Furin-mediated protein processing in infectious diseases and cancer. Clin Transl Immunol 8:. https://doi.org/10.1002/cti2.1073

58. Johnson BA, Xie X, Kalveram B, et al (2020) Furin Cleavage Site Is Key to SARS-CoV-2 Pathogenesis. BioRxiv Prepr Serv Biol. https://doi.org/10.1101/2020.08.26.268854

59. Peacock TP, Goldhill DH, Zhou J, et al (2020) The furin cleavage site of SARSCoV-2 spike protein is a key determinant for transmission due to enhanced replication in airway cells. bioRxiv 2020.09.30.318311. https://doi.org/10.1101/2020.09.30.318311

60. Anand P, Puranik A, Aravamudan M, et al (2020) SARS-CoV-2 strategically mimics proteolytic activation of human $\mathrm{ENaC}$. eLife 9:e58603. https://doi.org/10.7554/eLife.58603

61. Peckham D, McDermott MF, Savic S, Mehta A (2020) COVID-19 meets Cystic Fibrosis: for better or worse? Genes Immun 21:260-262. https://doi.org/10.1038/s41435-020-0103-y

62. Fainardi V, Longo F, Chetta A, et al (2020) SARS-CoV-2 Infection in patients with cystic fibrosis. An overwiew. Acta Bio Medica Atenei Parm 91:e2020035. https://doi.org/10.23750/abm.v91i3.10391

63. Belouzard S, Chu VC, Whittaker GR (2009) Activation of the SARS coronavirus spike protein via sequential proteolytic cleavage at two distinct sites. Proc Natl Acad Sci U S A 106:5871-5876. https://doi.org/10.1073/pnas.0809524106

64. Heald-Sargent T, Gallagher T (2012) Ready, Set, Fuse! The Coronavirus Spike Protein and Acquisition of Fusion Competence. Viruses 4:557-580. https://doi.org/10.3390/v4040557

65. Millet JK, Whittaker GR (2015) Host cell proteases: Critical determinants of coronavirus tropism and pathogenesis. Virus Res 202:120-134. https://doi.org/10.1016/j.virusres.2014.11.021

66. Park J-E, Li K, Barlan A, et al (2016) Proteolytic processing of Middle East respiratory syndrome coronavirus spikes expands virus tropism. Proc Natl Acad Sci U S A 113:12262-12267. https://doi.org/10.1073/pnas.1608147113

67. Walls AC, Tortorici MA, Snijder J, et al (2017) Tectonic conformational changes of a coronavirus spike glycoprotein promote membrane fusion. Proc Natl Acad Sci U S A 114:11157-11162. https://doi.org/10.1073/pnas.1708727114 
68. Millet JK, Whittaker GR (2014) Host cell entry of Middle East respiratory syndrome coronavirus after two-step, furin-mediated activation of the spike protein. Proc Natl Acad Sci U S A 111:15214-15219. https://doi.org/10.1073/pnas.1407087111

69. Wang Q, Zhang Y, Wu L, et al (2020) Structural and Functional Basis of SARSCoV-2 Entry by Using Human ACE2. Cell 181:894-904.e9. https://doi.org/10.1016/j.cell.2020.03.045

70. Molecular Basis for Pathogenicity of Human Coronaviruses. https://www.ncbi.nlm.nih.gov/pmc/articles/PMC7381773/. Accessed 28 Dec 2020

71. Li F (2014) Receptor Recognition Mechanisms of Coronaviruses: a Decade of Structural Studies. J Virol 89:1954-1964. https://doi.org/10.1128/JVI.02615-14

72. Zhou P, Yang X-L, Wang X-G, et al (2020) A pneumonia outbreak associated with a new coronavirus of probable bat origin. Nature 579:270-273. https://doi.org/10.1038/s41586-020-2012-7

73. Wan Y, Shang J, Graham R, et al (2020) Receptor Recognition by the Novel Coronavirus from Wuhan: an Analysis Based on Decade-Long Structural Studies of SARS Coronavirus. J Virol 94:. https://doi.org/10.1128/JVI.00127-20

74. Li F, Li W, Farzan M, Harrison SC (2005) Structure of SARS coronavirus spike receptor-binding domain complexed with receptor. Science 309:1864-1868. https://doi.org/10.1126/science.1116480

75. Wu K, Li W, Peng G, Li F (2009) Crystal structure of NL63 respiratory coronavirus receptor-binding domain complexed with its human receptor. Proc Natl Acad Sci 106:19970-19974. https://doi.org/10.1073/pnas.0908837106

76. Wang N, Shi X, Jiang L, et al (2013) Structure of MERS-CoV spike receptorbinding domain complexed with human receptor DPP4. Cell Res 23:986-993. https://doi.org/10.1038/cr.2013.92

77. Reguera J, Santiago C, Mudgal G, et al (2012) Structural bases of coronavirus attachment to host aminopeptidase $\mathrm{N}$ and its inhibition by neutralizing antibodies. PLoS Pathog 8:e1002859. https://doi.org/10.1371/journal.ppat.1002859

78. Peng G, Sun D, Rajashankar KR, et al (2011) Crystal structure of mouse coronavirus receptor-binding domain complexed with its murine receptor. Proc Natl Acad Sci U S A 108:10696-10701. https://doi.org/10.1073/pnas.1104306108

79. Structural analysis of major species barriers between humans and palm civets for severe acute respiratory syndrome coronavirus infections - PubMed. https://pubmed.ncbi.nlm.nih.gov/18448527/. Accessed 26 Dec 2020

80. Peng G, Xu L, Lin Y-L, et al (2012) Crystal structure of bovine coronavirus spike protein lectin domain. J Biol Chem 287:41931-41938.

https://doi.org/10.1074/jbc.M112.418210

81. Wang Q, Qi J, Yuan Y, et al (2014) Bat origins of MERS-CoV supported by bat coronavirus HKU4 usage of human receptor CD26. Cell Host Microbe 16:328-337. https://doi.org/10.1016/j.chom.2014.08.009

82. Wu K, Peng G, Wilken M, et al (2012) Mechanisms of host receptor adaptation by severe acute respiratory syndrome coronavirus. J Biol Chem 287:8904-8911. https://doi.org/10.1074/jbc.M111.325803

83. Yang Y, Du L, Liu C, et al (2014) Receptor usage and cell entry of bat coronavirus HKU4 provide insight into bat-to-human transmission of MERS 
coronavirus. Proc Natl Acad Sci U S A 111:12516-12521.

https://doi.org/10.1073/pnas.1405889111

84. Wu K, Chen L, Peng G, et al (2011) A virus-binding hot spot on human

angiotensin-converting enzyme 2 is critical for binding of two different coronaviruses.

J Virol 85:5331-5337. https://doi.org/10.1128/JVI.02274-10

85. Dove A (2001) The bittersweet promise of glycobiology. Nat Biotechnol 19:913917. https://doi.org/10.1038/nbt1001-913

86. Ghazarian H, Idoni B, Oppenheimer SB (2011) A glycobiology review: carbohydrates, lectins and implications in cancer therapeutics. Acta Histochem 113:236-247. https://doi.org/10.1016/j.acthis.2010.02.004

87. Schwegmann-Wessels C, Herrler G (2006) Sialic acids as receptor determinants for coronaviruses. Glycoconj J 23:51-58. https://doi.org/10.1007/s10719-006-5437-9

88. Walls AC, Tortorici MA, Frenz B, et al (2016) Glycan shield and epitope masking of a coronavirus spike protein observed by cryo-electron microscopy. Nat Struct Mol Biol 23:899-905. https://doi.org/10.1038/nsmb.3293

89. Xiong X, Tortorici MA, Snijder J, et al (2018) Glycan Shield and Fusion Activation of a Deltacoronavirus Spike Glycoprotein Fine-Tuned for Enteric Infections. J Virol 92:. https://doi.org/10.1128/JVI.01628-17

90. Yang Y, Liu C, Du L, et al (2015) Two Mutations Were Critical for Bat-to-Human Transmission of Middle East Respiratory Syndrome Coronavirus. J Virol 89:9119 9123. https://doi.org/10.1128/JVI.01279-15

91. Pallesen J, Wang N, Corbett KS, et al (2017) Immunogenicity and structures of a rationally designed prefusion MERS-CoV spike antigen. Proc Natl Acad Sci U S A 114:E7348-E7357. https://doi.org/10.1073/pnas.1707304114

92. Rossen JWA, de Beer R, Godeke G-J, et al (1998) The Viral Spike Protein Is Not Involved in the Polarized Sorting of Coronaviruses in Epithelial Cells. J Virol 72:497503

93. Grant OC, Montgomery D, Ito K, Woods RJ (2020) Analysis of the SARS-CoV-2 spike protein glycan shield: implications for immune recognition. BioRxiv Prepr Serv Biol. https://doi.org/10.1101/2020.04.07.030445

94. Watanabe Y, Allen JD, Wrapp D, et al (2020) Site-specific glycan analysis of the SARS-CoV-2 spike. Science 369:330-333. https://doi.org/10.1126/science.abb9983

95. Wang D, Baudys J, Bundy JL, et al (2020) Comprehensive Analysis of the Glycan Complement of SARS-CoV-2 Spike Proteins Using Signature lons-Triggered Electron-Transfer/Higher-Energy Collisional Dissociation (EThcD) Mass Spectrometry. Anal Chem 92:14730-14739. https://doi.org/10.1021/acs.analchem.0c03301

96. Sanda M, Morrison L, Goldman R (2020) N and O glycosylation of the SARSCoV-2 spike protein. BioRxiv Prepr Serv Biol. https://doi.org/10.1101/2020.07.05.187344

97. Casalino L, Gaieb Z, Goldsmith JA, et al (2020) Beyond Shielding: The Roles of Glycans in the SARS-CoV-2 Spike Protein. ACS Cent Sci 6:1722-1734. https://doi.org/10.1021/acscentsci.0c01056

98. Zhao P, Praissman JL, Grant OC, et al (2020) Virus-Receptor Interactions of Glycosylated SARS-CoV-2 Spike and Human ACE2 Receptor. Cell Host Microbe 28:586-601.e6. https://doi.org/10.1016/j.chom.2020.08.004 
99. Spaan W, Cavanagh D, Horzinek MC (1988) Coronaviruses: structure and genome expression. J Gen Virol 69 ( Pt 12):2939-2952. https://doi.org/10.1099/0022-1317-69-12-2939

100. Bosch BJ, van der Zee R, de Haan CAM, Rottier PJM (2003) The Coronavirus Spike Protein Is a Class I Virus Fusion Protein: Structural and Functional Characterization of the Fusion Core Complex. J Virol 77:8801-8811. https://doi.org/10.1128/JVI.77.16.8801-8811.2003

101. Li W, Moore MJ, Vasilieva N, et al (2003) Angiotensin-converting enzyme 2 is a functional receptor for the SARS coronavirus. Nature 426:450-454. https://doi.org/10.1038/nature02145

102. Hofmann H, Pyrc K, Hoek L van der, et al (2005) Human coronavirus NL63 employs the severe acute respiratory syndrome coronavirus receptor for cellular entry. Proc Natl Acad Sci 102:7988-7993. https://doi.org/10.1073/pnas.0409465102

103. Bosch BJ, Smits SL, Haagmans BL (2014) Membrane ectopeptidases targeted by human coronaviruses. Curr Opin Virol 6:55-60. https://doi.org/10.1016/j.coviro.2014.03.011

104. Solerte SB, Di Sabatino A, Galli M, Fiorina P (2020) Dipeptidyl peptidase-4 (DPP4) inhibition in COVID-19. Acta Diabetol 1-5. https://doi.org/10.1007/s00592020-01539-z

105. Raj VS, Mou H, Smits SL, et al (2013) Dipeptidyl peptidase 4 is a functional receptor for the emerging human coronavirus-EMC. Nature 495:251-254. https://doi.org/10.1038/nature12005

106. Delmas B, Gelfi J, L'Haridon R, et al (1992) Aminopeptidase N is a major receptor for the entero-pathogenic coronavirus TGEV. Nature 357:417-420. https://doi.org/10.1038/357417a0

107. Godet M, Grosclaude J, Delmas B, Laude H (1994) Major receptor-binding and neutralization determinants are located within the same domain of the transmissible gastroenteritis virus (coronavirus) spike protein. J Virol 68:8008-8016.

https://doi.org/10.1128/JVI.68.12.8008-8016.1994

108. Miura HS, Nakagaki K, Taguchi F (2004) N-Terminal Domain of the Murine Coronavirus Receptor CEACAM1 Is Responsible for Fusogenic Activation and Conformational Changes of the Spike Protein. J Virol 78:216-223.

https://doi.org/10.1128/JVI.78.1.216-223.2004

109. Jeffers SA, Tusell SM, Gillim-Ross L, et al (2004) CD209L (L-SIGN) is a receptor for severe acute respiratory syndrome coronavirus. Proc Natl Acad Sci U S A 101:15748-15753. https://doi.org/10.1073/pnas.0403812101

110. Cantuti-Castelvetri L, Ojha R, Pedro LD, et al (2020) Neuropilin-1 facilitates SARS-CoV-2 cell entry and infectivity. Science 370:856-860. https://doi.org/10.1126/science.abd2985

111. Davies J, Randeva HS, Chatha K, et al (2020) Neuropilin-1 as a new potential SARS-CoV-2 infection mediator implicated in the neurologic features and central nervous system involvement of COVID-19. Mol Med Rep 22:4221-4226. https://doi.org/10.3892/mmr.2020.11510

112. Daly JL, Simonetti B, Klein K, et al (2020) Neuropilin-1 is a host factor for SARSCoV-2 infection. Science 370:861-865. https://doi.org/10.1126/science.abd3072

113. Wang K, Chen W, Zhang Z, et al (2020) CD147-spike protein is a novel route for 
SARS-CoV-2 infection to host cells. Signal Transduct Target Ther 5:283. https://doi.org/10.1038/s41392-020-00426-x

114. Ulrich H, Pillat MM (2020) CD147 as a Target for COVID-19 Treatment: Suggested Effects of Azithromycin and Stem Cell Engagement. Stem Cell Rev Rep 16:434-440. https://doi.org/10.1007/s12015-020-09976-7

115. Essahib W, Verheyen G, Tournaye H, Van de Velde H (2020) SARS-CoV-2 host receptors ACE2 and CD147 (BSG) are present on human oocytes and blastocysts. J Assist Reprod Genet 37:2657-2660. https://doi.org/10.1007/s10815-020-01952-x

116. Aguiar JA, Tremblay BJ-M, Mansfield MJ, et al (2020) Gene expression and in situ protein profiling of candidate SARS-CoV-2 receptors in human airway epithelial cells and lung tissue. Eur Respir J 56:. https://doi.org/10.1183/13993003.011232020

117. Chu H, Chan C-M, Zhang X, et al (2018) Middle East respiratory syndrome coronavirus and bat coronavirus HKU9 both can utilize GRP78 for attachment onto host cells. J Biol Chem 293:11709-11726. https://doi.org/10.1074/jbc.RA118.001897

118. Valencia I, Peiró C, Lorenzo Ó, et al (2020) DPP4 and ACE2 in Diabetes and COVID-19: Therapeutic Targets for Cardiovascular Complications? Front Pharmacol 11:. https://doi.org/10.3389/fphar.2020.01161

119. Du L, Zhao G, Kou Z, et al (2013) Identification of a Receptor-Binding Domain in the S Protein of the Novel Human Coronavirus Middle East Respiratory Syndrome Coronavirus as an Essential Target for Vaccine Development. J Virol 87:9939-9942. https://doi.org/10.1128/JVI.01048-13

120. Mou H, Raj VS, van Kuppeveld FJM, et al (2013) The Receptor Binding Domain of the New Middle East Respiratory Syndrome Coronavirus Maps to a 231-Residue Region in the Spike Protein That Efficiently Elicits Neutralizing Antibodies. J Virol 87:9379-9383. https://doi.org/10.1128/JVI.01277-13

121. Sungnak W, Huang N, Bécavin C, et al (2020) SARS-CoV-2 entry factors are highly expressed in nasal epithelial cells together with innate immune genes. Nat Med 26:681-687. https://doi.org/10.1038/s41591-020-0868-6

122. Hoffmann M, Kleine-Weber H, Schroeder S, et al (2020) SARS-CoV-2 Cell Entry Depends on ACE2 and TMPRSS2 and Is Blocked by a Clinically Proven Protease Inhibitor. Cell 181:271-280.e8. https://doi.org/10.1016/j.cell.2020.02.052

123. Yang J, Petitjean SJL, Koehler M, et al (2020) Molecular interaction and inhibition of SARS-CoV-2 binding to the ACE2 receptor. Nat Commun 11:4541. https://doi.org/10.1038/s41467-020-18319-6

124. Samavati L, Uhal BD (2020) ACE2, Much More Than Just a Receptor for SARSCOV-2. Front Cell Infect Microbiol 10:. https://doi.org/10.3389/fcimb.2020.00317

125. Yan R, Zhang Y, Li Y, et al (2020) Structural basis for the recognition of SARSCoV-2 by full-length human ACE2. Science 367:1444-1448. https://doi.org/10.1126/science.abb2762

126. Barchetta I, Cavallo MG, Baroni MG (2020) COVID-19 and diabetes: Is this association driven by the DPP4 receptor? Potential clinical and therapeutic implications. Diabetes Res Clin Pract 163:108165.

https://doi.org/10.1016/j.diabres.2020.108165

127. Kim SY, Jin W, Sood A, et al (2020) Characterization of heparin and severe 
acute respiratory syndrome-related coronavirus 2 (SARS-CoV-2) spike glycoprotein binding interactions. Antiviral Res 181:104873.

https://doi.org/10.1016/j.antiviral.2020.104873

128. Lonsdale J, Thomas J, Salvatore M, et al (2013) The Genotype-Tissue

Expression (GTEx) project. Nat Genet 45:580-585. https://doi.org/10.1038/ng.2653

129. Shi L, Mao C, Xu Z, Zhang L (2010) Angiotensin-converting enzymes and drug discovery in cardiovascular diseases. Drug Discov Today 15:332-341.

https://doi.org/10.1016/j.drudis.2010.02.003

130. Donoghue M, Hsieh F, Baronas E, et al (2000) A novel angiotensin-converting enzyme-related carboxypeptidase (ACE2) converts angiotensin I to angiotensin 1-9. Circ Res 87:E1-9. https://doi.org/10.1161/01.res.87.5.e1

131. Turner AJ, Hooper NM (2002) The angiotensin-converting enzyme gene family: genomics and pharmacology. Trends Pharmacol Sci 23:177-183.

https://doi.org/10.1016/S0165-6147(00)01994-5

132. Perlot T, Penninger JM (2013) ACE2 - from the renin-angiotensin system to gut microbiota and malnutrition. Microbes Infect 15:866-873.

https://doi.org/10.1016/j.micinf.2013.08.003

133. Imai Y, Kuba K, Rao S, et al (2005) Angiotensin-converting enzyme 2 protects from severe acute lung failure. Nature 436:112-116. https://doi.org/10.1038/nature03712

134. Kuba K, Imai Y, Rao S, et al (2005) A crucial role of angiotensin converting enzyme 2 (ACE2) in SARS coronavirus-induced lung injury. Nat Med 11:875-879. https://doi.org/10.1038/nm1267

135. Inference of macromolecular assemblies from crystalline state - PubMed. https://pubmed.ncbi.nlm.nih.gov/17681537/. Accessed 5 Jan 2021

136. Yi L, Gu YH, Wang XL, et al (2006) Association of ACE, ACE2 and UTS2 polymorphisms with essential hypertension in Han and Dongxiang populations from north-western China. J Int Med Res 34:272-283.

https://doi.org/10.1177/147323000603400306

137. Niu W, Qi Y, Hou S, et al (2007) Correlation of angiotensin-converting enzyme 2 gene polymorphisms with stage 2 hypertension in Han Chinese. Transl Res J Lab Clin Med 150:374-380. https://doi.org/10.1016/j.trsl.2007.06.002

138. Li F, Li W, Farzan M, Harrison SC (2006) Interactions between SARS coronavirus and its receptor. Adv Exp Med Biol 581:229-234. https://doi.org/10.1007/978-0-387-33012-9_38

139. Shang J, Ye G, Shi K, et al (2020) Structural basis of receptor recognition by SARS-CoV-2. Nature 581:221-224. https://doi.org/10.1038/s41586-020-2179-y

140. Lan J, Ge J, Yu J, et al (2020) Structure of the SARS-CoV-2 spike receptorbinding domain bound to the ACE2 receptor. Nature 581:215-220. https://doi.org/10.1038/s41586-020-2180-5

141. Wrapp D, Wang N, Corbett KS, et al (2020) Cryo-EM structure of the 2019-nCoV spike in the prefusion conformation. Science 367:1260-1263.

https://doi.org/10.1126/science.abb2507

142. Washington NL, Gangavarapu K, Zeller M, et al (2021) Genomic epidemiology identifies emergence and rapid transmission of SARS-CoV-2 B.1.1.7 in the United States. medRxiv 2021.02.06.21251159. 
https://doi.org/10.1101/2021.02.06.21251159

143. Rapid increase of a SARS-CoV-2 variant with multiple spike protein mutations observed in the United Kingdom. 13

144. Choi B, Choudhary MC, Regan J, et al (2020) Persistence and Evolution of SARS-CoV-2 in an Immunocompromised Host. N Engl J Med 383:2291-2293. https://doi.org/10.1056/NEJMc2031364

145. Toovey OTR, Harvey KN, Bird PW, Tang JW-TW-T (2021) Introduction of Brazilian SARS-CoV-2 484K.V2 related variants into the UK. J Infect. https://doi.org/10.1016/j.jinf.2021.01.025

146. Galloway SE, Paul P, MacCannell DR, et al (2021) Emergence of SARS-CoV-2 B.1.1.7 Lineage - United States, December 29, 2020-January 12, 2021. MMWR Morb Mortal Wkly Rep 70:95-99. https://doi.org/10.15585/mmwr.mm7003e2

147. Jangra S, Ye C, Rathnasinghe R, et al (2021) The E484K mutation in the SARSCoV-2 spike protein reduces but does not abolish neutralizing activity of human convalescent and post-vaccination sera. MedRxiv Prepr Serv Health Sci. https://doi.org/10.1101/2021.01.26.21250543

148. Thomson EC, Rosen LE, Shepherd JG, et al (2021) Circulating SARS-CoV-2 spike N439K variants maintain fitness while evading antibody-mediated immunity. Cell. https://doi.org/10.1016/j.cell.2021.01.037

149. Weisblum Y, Schmidt F, Zhang F, et al (2020) Escape from neutralizing antibodies by SARS-CoV-2 spike protein variants. eLife 9:.

https://doi.org/10.7554/eLife.61312

150. Wang P, Liu L, Iketani S, et al (2021) Increased Resistance of SARS-CoV-2 Variants B.1.351 and B.1.1.7 to Antibody Neutralization. BioRxiv Prepr Serv Biol. https://doi.org/10.1101/2021.01.25.428137

151. Wu K, Werner AP, Moliva JI, et al (2021) mRNA-1273 vaccine induces neutralizing antibodies against spike mutants from global SARS-CoV-2 variants. BioRxiv Prepr Serv Biol. https://doi.org/10.1101/2021.01.25.427948

152. Moderna COVID-19 Vaccine Retains Neutralizing Activity Against Emerging Variants First Identified in the U.K. and the Republic of South Africa | Moderna, Inc. https://investors.modernatx.com/news-releases/news-release-details/modernacovid-19-vaccine-retains-neutralizing-activity-against/. Accessed 12 Feb 2021

153. Xie X, Liu Y, Liu J, et al (2021) Neutralization of SARS-CoV-2 spike 69/70 deletion, E484K, and N501Y variants by BNT162b2 vaccine-elicited sera. BioRxiv Prepr Serv Biol. https://doi.org/10.1101/2021.01.27.427998

154. (2021) Pfizer BioNTech vaccine likely to be effective against B1.1.7 strain of SARS-CoV-2. In: Univ. Camb. https://www.cam.ac.uk/research/news/pfizerbiontech-vaccine-likely-to-be-effective-against-b117-strain-of-sars-cov-2. Accessed 12 Feb 2021

155. Andreano E, Piccini G, Licastro D, et al (2020) SARS-CoV-2 escape in vitro from a highly neutralizing COVID-19 convalescent plasma. BioRxiv Prepr Serv Biol. https://doi.org/10.1101/2020.12.28.424451

156. Di Natale C, La Manna S, De Benedictis I, et al (2020) Perspectives in PeptideBased Vaccination Strategies for Syndrome Coronavirus 2 Pandemic. Front Pharmacol 11:578382. https://doi.org/10.3389/fphar.2020.578382

157. Le Bert N, Tan AT, Kunasegaran K, et al (2020) SARS-CoV-2-specific T cell 
immunity in cases of COVID-19 and SARS, and uninfected controls. Nature 584:457-462. https://doi.org/10.1038/s41586-020-2550-z

158. Nelde A, Bilich T, Heitmann JS, et al (2021) SARS-CoV-2-derived peptides define heterologous and COVID-19-induced T cell recognition. Nat Immunol 22:7485. https://doi.org/10.1038/s41590-020-00808-x

159. Mateus J, Grifoni A, Tarke A, et al (2020) Selective and cross-reactive SARSCoV-2 T cell epitopes in unexposed humans. Science 370:89-94. https://doi.org/10.1126/science.abd3871

160. Shomuradova AS, Vagida MS, Sheetikov SA, et al (2020) SARS-CoV-2 Epitopes Are Recognized by a Public and Diverse Repertoire of Human T Cell Receptors. Immunity 53:1245-1257.e5. https://doi.org/10.1016/j.immuni.2020.11.004

161. Mahajan S, Kode V, Bhojak K, et al (2020) Immunodominant T-cell epitopes from the SARS-CoV-2 spike antigen reveal robust pre-existing T-cell immunity in unexposed individuals. bioRxiv 2020.11.03.367375. https://doi.org/10.1101/2020.11.03.367375

162. Crooke SN, Ovsyannikova IG, Kennedy RB, Poland GA (2020) Immunoinformatic identification of $B$ cell and T cell epitopes in the SARS-CoV-2 proteome. Sci Rep 10:14179. https://doi.org/10.1038/s41598-020-70864-8

163. Lin L, Ting S, Yufei H, et al (2020) Epitope-based peptide vaccines predicted against novel coronavirus disease caused by SARS-CoV-2. Virus Res 288:198082. https://doi.org/10.1016/j.virusres.2020.198082

164. Noorimotlagh Z, Karami C, Mirzaee SA, et al (2020) Immune and bioinformatics identification of $T$ cell and $B$ cell epitopes in the protein structure of SARS-CoV-2: A systematic review. Int Immunopharmacol 86:106738. https://doi.org/10.1016/j.intimp.2020.106738

165. Naz A, Shahid F, Butt TT, et al (2020) Designing Multi-Epitope Vaccines to Combat Emerging Coronavirus Disease 2019 (COVID-19) by Employing ImmunoInformatics Approach. Front Immunol 11:1663.

https://doi.org/10.3389/fimmu.2020.01663

166. Chen Z, Ruan P, Wang L, et al (2021) T and B cell Epitope analysis of SARSCoV-2 S protein based on immunoinformatics and experimental research. $\mathrm{J}$ Cell Mol Med 25:1274-1289. https://doi.org/10.1111/jcmm.16200

167. Zou X, Chen K, Zou J, et al (2020) Single-cell RNA-seq data analysis on the receptor ACE2 expression reveals the potential risk of different human organs vulnerable to 2019-nCoV infection. Front Med 14:185-192. https://doi.org/10.1007/s11684-020-0754-0

168. Qi F, Qian S, Zhang S, Zhang Z (2020) Single cell RNA sequencing of 13 human tissues identify cell types and receptors of human coronaviruses. Biochem Biophys Res Commun 526:135-140. https://doi.org/10.1016/j.bbrc.2020.03.044

169. Yeager CL, Ashmun RA, Williams RK, et al (1992) Human aminopeptidase $\mathrm{N}$ is a receptor for human coronavirus 229E. Nature 357:420-422. https://doi.org/10.1038/357420a0

170. Hoffmann M, Kleine-Weber H, Krüger N, et al (2020) The novel coronavirus 2019 (2019-nCoV) uses the SARS-coronavirus receptor ACE2 and the cellular protease TMPRSS2 for entry into target cells. bioRxiv 2020.01.31.929042.

https://doi.org/10.1101/2020.01.31.929042 
171. Ahrén B (2012) DPP-4 inhibition and islet function. J Diabetes Investig 3:3-10. https://doi.org/10.1111/j.2040-1124.2011.00184.x

172. Kleine-Weber H, Schroeder S, Krüger N, et al (2020) Polymorphisms in dipeptidyl peptidase 4 reduce host cell entry of Middle East respiratory syndrome coronavirus. Emerg Microbes Infect 9:155-168. https://doi.org/10.1080/22221751.2020.1713705

173. Chen L, Lin Y-L, Peng G, Li F (2012) Structural basis for multifunctional roles of mammalian aminopeptidase N. Proc Natl Acad Sci U S A 109:17966-17971. https://doi.org/10.1073/pnas.1210123109

174. Mina-Osorio P (2008) The moonlighting enzyme CD13: old and new functions to target. Trends Mol Med 14:361-371. https://doi.org/10.1016/j.molmed.2008.06.003

175. Kolb AF, Hegyi A, Siddell SG (1997) Identification of residues critical for the human coronavirus 229E receptor function of human aminopeptidase N. J Gen Virol 78 ( Pt 11):2795-2802. https://doi.org/10.1099/0022-1317-78-11-2795

176. Lowes H, Robertson F, Pyle A, et al (2020) The Human Coronavirus Receptor ANPEP (CD13) Is Overexpressed in Parkinson's Disease. Mov Disord Off J Mov Disord Soc 35:2134-2136. https://doi.org/10.1002/mds.28354

177. Pavel A, Murray DK, StoessI AJ (2020) COVID-19 and selective vulnerability to Parkinson's disease. Lancet Neurol 19:719. https://doi.org/10.1016/S14744422(20)30269-6

178. Hulswit RJG, de Haan C a. M, Bosch B-J (2016) Coronavirus Spike Protein and Tropism Changes. Adv Virus Res 96:29-57. https://doi.org/10.1016/bs.aivir.2016.08.004

179. The spike glycoprotein of murine coronavirus MHV-JHM mediates receptorindependent infection and spread in the central nervous systems of Ceacam1a-/Mice - PubMed. https://pubmed.ncbi.nlm.nih.gov/18003729/. Accessed 26 Dec 2020

180. Millet JK, Jaimes JA, Whittaker GR (2020) Molecular diversity of coronavirus host cell entry receptors. FEMS Microbiol Rev. https://doi.org/10.1093/femsre/fuaa057

181. Jeffers SA, Hemmila EM, Holmes KV (2006) Human coronavirus 229E can use CD209L (L-SIGN) to enter cells. Adv Exp Med Biol 581:265-269.

https://doi.org/10.1007/978-0-387-33012-9_44

182. Amraei R, Yin W, Napoleon MA, et al (2020) CD209L/L-SIGN and CD209/DCSIGN act as receptors for SARS-CoV-2 and are differentially expressed in lung and kidney epithelial and endothelial cells. bioRxiv. https://doi.org/10.1101/2020.06.22.165803

183. Multifaceted Role of Neuropilins in the Immune System: Potential Targets for Immunotherapy. https://www.ncbi.nlm.nih.gov/pmc/articles/PMC5641316/. Accessed 26 Dec 2020

184. Neuropilins are multifunctional coreceptors involved in tumor initiation, growth, metastasis and immunity. https://www.ncbi.nlm.nih.gov/pmc/articles/PMC3660061/. Accessed 26 Dec 2020

185. Geretti E, Shimizu A, Klagsbrun M (2008) Neuropilin structure governs VEGF and semaphorin binding and regulates angiogenesis. Angiogenesis 11:31-39. https://doi.org/10.1007/s10456-008-9097-1

186. Chen Z, Mi L, Xu J, et al (2005) Function of HAb18G/CD147 in invasion of host cells by severe acute respiratory syndrome coronavirus. J Infect Dis 191:755-760. 
https://doi.org/10.1086/427811

187. Su H, Wan C, Wang Z-D, et al (2020) Expression of CD147 and Cyclophilin A in Kidneys of Patients with COVID-19. Clin J Am Soc Nephrol CJASN.

https://doi.org/10.2215/CJN.09440620

188. Crosnier C, Bustamante LY, Bartholdson SJ, et al (2011) Basigin is a receptor essential for erythrocyte invasion by Plasmodium falciparum. Nature 480:534-537. https://doi.org/10.1038/nature10606

189. Odièvre $\mathrm{M}-\mathrm{H}$, Bony $\mathrm{V}$, Benkerrou $\mathrm{M}$, et al (2008) Modulation of erythroid adhesion receptor expression by hydroxyurea in children with sickle cell disease. Haematologica 93:502-510. https://doi.org/10.3324/haematol.12070

190. Pistol G, Matache C, Calugaru A, et al (2007) Roles of CD147 on T lymphocytes activation and MMP-9 secretion in Systemic Lupus Erythematosus. J Cell Mol Med 11:339-348. https://doi.org/10.1111/j.1582-4934.2007.00022.x

191. Guillot S, Delaval P, Brinchault G, et al (2006) Increased extracellular matrix metalloproteinase inducer (EMMPRIN) expression in pulmonary fibrosis. Exp Lung Res 32:81-97. https://doi.org/10.1080/01902140600710512

192. Tan L, Wang Q, Zhang D, et al (2020) Lymphopenia predicts disease severity of COVID-19: a descriptive and predictive study. Signal Transduct Target Ther 5:33. https://doi.org/10.1038/s41392-020-0148-4

193. Song X, Hu W, Yu H, et al (2020) Little to no expression of angiotensinconverting enzyme-2 on most human peripheral blood immune cells but highly expressed on tissue macrophages. Cytom Part J Int Soc Anal Cytol. https://doi.org/10.1002/cyto.a.24285

194. Li M-Y, Li L, Zhang Y, Wang X-S (2020) Expression of the SARS-CoV-2 cell receptor gene ACE2 in a wide variety of human tissues. Infect Dis Poverty 9:45. https://doi.org/10.1186/s40249-020-00662-x

195. SARS-CoV-2 strategically mimics proteolytic activation of human ENaC PubMed. https://pubmed.ncbi.nlm.nih.gov/32452762/. Accessed 26 Dec 2020

196. Singh M, Bansal V, Feschotte C (2020) A Single-Cell RNA Expression Map of Human Coronavirus Entry Factors. Cell Rep 32:108175. https://doi.org/10.1016/j.celrep.2020.108175

197. DNA methylation and gene expression pattern of ACE2 and TMPRSS2 genes in saliva samples of patients with SARS-CoV-2 infection | medRxiv. https://www.medrxiv.org/content/10.1101/2020.10.24.20218727v1. Accessed 20 Dec 2020

198. Röhnert P, Schmidt W, Emmerlich P, et al (2012) Dipeptidyl peptidase IV, aminopeptidase $\mathrm{N}$ and DPIV/APN-like proteases in cerebral ischemia. J Neuroinflammation 9:44. https://doi.org/10.1186/1742-2094-9-44

199. Aliee H, Massip F, Qi C, et al (2020) Determinants of SARS-CoV-2 receptor gene expression in upper and lower airways. MedRxiv Prepr Serv Health Sci. https://doi.org/10.1101/2020.08.31.20169946

200. Damas J, Hughes GM, Keough KC, et al (2020) Broad host range of SARS-CoV2 predicted by comparative and structural analysis of ACE2 in vertebrates. Proc Natl Acad Sci U S A 117:22311-22322. https://doi.org/10.1073/pnas.2010146117 201. Zhang L, Jackson CB, Mou H, et al (2020) The D614G mutation in the SARSCoV-2 spike protein reduces S1 shedding and increases infectivity. BioRxiv Prepr 
Serv Biol. https://doi.org/10.1101/2020.06.12.148726

202. Plante JA, Liu Y, Liu J, et al (2020) Spike mutation D614G alters SARS-CoV-2 fitness and neutralization susceptibility. BioRxiv Prepr Serv Biol. https://doi.org/10.1101/2020.09.01.278689

203. Pang H-B, Braun GB, Friman T, et al (2014) An endocytosis pathway initiated through neuropilin-1 and regulated by nutrient availability. Nat Commun 5:4904. https://doi.org/10.1038/ncomms5904

204. Li Y, Zhang Z, Yang L, et al (2020) The MERS-CoV Receptor DPP4 as a Candidate Binding Target of the SARS-CoV-2 Spike. iScience 23:101160. https://doi.org/10.1016/j.isci.2020.101160

205. Phyu Khin P, Cha S-H, Jun H-S, Lee JH (2020) A potential therapeutic combination for treatment of COVID-19: Synergistic effect of DPP4 and RAAS suppression. Med Hypotheses 144:110186. https://doi.org/10.1016/j.mehy.2020.110186

206. Ibricevic A, Pekosz A, Walter MJ, et al (2006) Influenza Virus Receptor Specificity and Cell Tropism in Mouse and Human Airway Epithelial Cells. J Virol 80:7469-7480. https://doi.org/10.1128/JVI.02677-05

207. Bowers JR, Readler JM, Sharma P, Excoffon KJDA (2017) Poliovirus Receptor: More than a simple viral receptor. Virus Res 242:1-6. https://doi.org/10.1016/j.virusres.2017.09.001

208. Dai L, Gao GF (2020) Viral targets for vaccines against COVID-19. Nat Rev Immunol 1-10. https://doi.org/10.1038/s41577-020-00480-0

209. Manfredonia I, Nithin C, Ponce-Salvatierra A, et al (2020) Genome-wide mapping of SARS-CoV-2 RNA structures identifies therapeutically-relevant elements. Nucleic Acids Res 48:12436-12452. https://doi.org/10.1093/nar/gkaa1053 